\title{
Sand transport processes and bed level changes induced by two alternating laboratory swash events
}

\author{
Joep van der Zanden ${ }^{\mathrm{a}, *}$, Iván Cáceres ${ }^{\mathrm{b}}$, Sonja Eichentopf ${ }^{\mathrm{c}}$, Jan S. \\ Ribberink $^{\mathrm{a}}$, Jebbe J. van der Werf ${ }^{\mathrm{d}, \mathrm{a}}$, José M. Alsina ${ }^{\mathrm{b}}$ \\ ${ }^{a}$ Marine and Fluvial Systems group, University of Twente, Drienerlolaan 5, 7522 NB \\ Enschede, Netherlands \\ ${ }^{b}$ Laboratori dEnginyeria Marítima, Universitat Politecnica de Catalunya, C. Jordi \\ Girona, 1-308034 Barcelona, Spain \\ ${ }^{c}$ Department of Civil and Environmental Engineering, Imperial College London, South \\ Kensington Campus, SW7 2AZ, UK \\ ${ }^{d}$ Deltares, P.O. Box 177, 2600 MH Delft, Netherlands
}

\begin{abstract}
Sand transport processes and net transport rates are studied in a largescale laboratory swash zone. Bichromatic waves with a phase modulation were generated, producing two continuously alternating swash events that have similar offshore wave statistics but which differ in terms of wave-swash interactions. Measured sand suspension and sheet flow dynamics show strong temporal and spatial variability, related to variations in flow velocity and locations of wave capture and wave-backwash interactions. Suspended and sheet flow layer transport rates in the lower swash zone are generally of same magnitude, but sheet flow exceeds the suspended load transport by up to a factor four during the early uprush. The bed level near the inner surf zone is relatively steady during a swash cycle, but changes of $\mathcal{O}(\mathrm{cm} / \mathrm{s})$ are measured near the mid swash zone where wave-swash interactions lead
\end{abstract}

\footnotetext{
*Corresponding author

Email address: vanderzandenjoep@gmail.com (Joep van der Zanden )
} 
to strongly non-uniform flows. The two alternating swash events produce a dynamic equilibrium, with bed level changes up to a few $\mathrm{mm}$ induced by single swash events, but with net morphodynamic change over multiple events that is two orders of magnitude lower. Most of the intra-swash and the single-event-averaged bed level changes in the swash zone are caused by a redistribution of sediment within the swash. The transport of sediment across the surf-swash boundary is minor at intra-swash time scale, but becomes increasingly significant at swash-averaged time scales or longer (i.e., averaged over multiple swash events).

\section{Highlights:}

- Large-scale wave flume experiments involving two alternating bichromatic wave induced swash events.

- Sediment mobilization as sheet load and suspended load increases substantially from inner surf to lower swash zone.

- Sheet flow transport dominates the total transport during the early uprush and during instants of strong wave-backwash interactions.

- Single swash events can produce much greater net transport rates and bed level changes than the overall trend over multiple events.

- For the present conditions, the net sediment exchange between swash and surf zone is low and sediment is mainly redistributed within the swash.

Keywords: Swash zone, sediment transport, bed level change, wave groups, beach morphology, large-scale wave flume, sheet flow 
1

2

\section{Introduction}

The swash zone is the part of the beach that is alternately inundated and exposed by the flow uprush and backwash. The combination of unsteady flows, high turbulence levels, large sediment transport rates and rapid bed level changes makes the swash a highly dynamic region (Masselink and Puleo, 2006; Brocchini and Baldock, 2008; Chardón-Maldonado et al., 2016). Processes in and near the swash zone ultimately determine whether sand is stored on the upper beach or transported offshore, hence controlling shoreline evolution. However, wave-averaged numerical models that are presently used in coastal engineering practice encounter great difficulties to accurately reproduce the morphologic evolution of the shoreline (van Rijn et al., 2013), which reflects a limited understanding of sand transport in the swash zone. Therefore, a better insight into the processes driving morphologic change in the swash is of vital importance to better understand and predict coastal erosion and sedimentation by natural processes or by human interferences.

A typical swash event consists of an uprush (incident wave running up a beach) and a backwash (run-down of the flow towards the sea). The hydrodynamics of single swash events, i.e., generated by solitary waves or dam breaks, have been extensively studied through experiments (e.g. Barnes et al., 2009; Kikkert et al., 2012, 2013; O'Donoghue et al., 2010; Pujara et al., 2015a; Higuera et al., 2018) and numerical simulations (e.g. Shen and Meyer, 1963; Hibberd and Peregrine, 1979; Barnes and Baldock, 2010; Briganti et al., 2011; Postacchini et al., 2014; Pintado-Patiño et al., 2015; Kim et al., 2017). During the uprush phase, the decelerating bore climbs the beach. The leading edge of the uprush bore is characterized by high bed shear stresses, which 
relate to the limited time for development of the boundary layer (Kikkert et al., 2012; Pintado-Patiño et al., 2015) and to the downward transport of fluid with high landward momentum by the converging flow in the swash tip (Barnes et al., 2009; Sou and Yeh, 2011; Baldock et al., 2014). The leading edge of the uprush is further characterized by high turbulent kinetic energy, which dissipates rapidly after passage of the uprush bore (O'Donoghue et al., 2010; Kikkert et al., 2012). After flow reversal, the flow accelerates in seaward direction and the bed shear stress increases progressively as the boundary layer develops. Free-stream velocities and bed shear stress reach a maximum in seaward direction during the mid backwash, before the flow decelerates during the final backwash stage.

The flow complexity increases for swash events driven by multiple waves, where the arrival of successive waves at the beach can lead to wave-swash interactions during uprush and backwash (Peregrine, 1974). A swash bore overtaking a preceding bore during the uprush is typically termed "wave capture" while an incident bore arriving during a preceding backwash leads to a "wave-backwash interaction" (Hughes and Moseley, 2007; Cáceres and Alsina, 2012). Wave-backwash interactions can be classified as "weak", when the incident wave has higher momentum than the backwash flow and continues to propagate towards the beach, or "strong", when the incident wave and backwash flow have similar momentum and the incident wave is halted or washed seaward (Hughes and Moseley, 2007; Cáceres and Alsina, 2012; Chen et al., 2016). Detailed observations and numerical simulations show that such interactions lead to strong velocity shearing, flow separation and vortex formation (Sou and Yeh, 2011; Pujara et al., 2015b; Chen et al., 2016; 
Higuera et al., 2018).

On sandy beaches, the energetic flow conditions in the swash lead to the transport of sediment as sheet flow and suspended load. The sheet flow layer is the thin (up to a few cm thickness) layer of high sand concentration directly above the non-moving bed, typically defined as the transport layer for which intergranular and sediment-flow interaction forces are significant (DohmenJanssen et al., 2001). Sediment grains lifted to higher elevations form the suspended load. Recent swash measurements indicate that suspended and sheet flow transport rates are of similar magnitude (Ruju et al., 2016; Puleo et al., 2016; Wu et al., 2016). Depending on wave conditions, sand type, and stage of the swash cycle, one transport mode may dominate over the other.

Sand suspension in the swash is not only controlled by local pick-up and deposition but also by cross-shore advection (Kobayashi and Johnson, 2001; Pritchard and Hogg, 2005; Alsina et al., 2009). Sediment pick-up in the swash is associated with high flow speeds and turbulence levels (Osborne and Rooker, 1999; Puleo et al., 2000; Aagaard and Hughes, 2006; Alsina and Cáceres, 2011). The suspended sand concentration is maximum during the early uprush, when both bed shear stress and turbulence levels are high, and during the mid to late backwash stage, when flow velocities reach a maximum in offshore direction (Osborne and Rooker, 1999; Butt and Russell, 1999; Masselink et al., 2005). Sand suspension has further been associated with wave capture and wave-backwash interaction events that drive turbulent mixing and pick-up from the bed (Hughes and Moseley, 2007; Cáceres and Alsina, 2012; Alsina et al., 2012, 2018).

Sheet flow layer (SFL) dynamics have been extensively studied in oscil- 
latory flow tunnels (Ribberink and Al-Salem, 1995; Hassan and Ribberink, 2005) and in wave flumes involving non-breaking (Dohmen-Janssen and Hanes, 2002, 2005; Schretlen, 2012) and breaking (Mieras et al., 2017; van der Zanden et al., 2017; Fromant et al., 2018) waves. In such conditions, sediment is eroded from the bed and brought upward during maximum velocity magnitudes, and settles when the velocity forcing reduces. As a result of this predominantly local vertical sediment exchange, the SFL grows and decays during each wave half cycle. Although the SFL in the swash exhibits similar concentration distributions to observations under non-breaking waves (Lanckriet et al., 2014; van der Zanden et al., 2015), its response to the freestream velocity is notably different. Firstly, because of the aforementioned converging flows and boundary layer processes that affect the bed shear stress during uprush and backwash. Secondly, additional forcing such as horizontal pressure gradients, turbulence originating from swash bores, and wave-swash interactions can enhance sediment mobilization and increase the SFL thickness (Lanckriet and Puleo, 2015; van der Zanden et al., 2015). Thirdly, the SFL dynamics are not only controlled by vertical processes but also by the cross-shore sand advection within the swash (van der Zanden et al., 2015). The latter is especially significant for narrow-band wave conditions that generate swash events with relatively high cross-shore excursion (Alsina et al., 2018). Parameterizations for sheet flow layer thickness in the swash have been presented (Lanckriet and Puleo, 2015), but the accurate simulation of advection-dominated SFL dynamics and transport rates may require more advanced advection-diffusion-type models (van der Zanden et al., 2015).

The high instantaneous and net sand transport rates in the swash have 
been measured using sediment traps on natural beaches (Masselink and Hughes, 1998; Jackson et al., 2004) and in laboratory flumes (O’Donoghue et al., 2016; Alsina et al., 2009), or by inferring the net transport from exposed bed level measurements (Blenkinsopp et al., 2011). Sediment loads and transport rates are generally highest in the lower and mid swash zones, close to the surf-swash boundary (Masselink and Hughes, 1998; Jackson et al., 2004). Within a swash event, sediment is transported landward during the uprush and seaward during the backwash. This cross-shore sand exchange leads to bed level fluctuations at intra-swash time scales, as shown by field measurements (Puleo et al., 2014), laboratory observations (Alsina et al., 2018), and numerical model simulations (Zhu and Dodd, 2013, 2015; Ruffini et al., 2019).

Net (i.e., swash-averaged) transport and bed level changes are generally considered to result from an imbalance between the landward uprush and seaward backwash transport. Net transport rates by different events within one tidal cycle may vary strongly in terms of direction and magnitude, which is partly attributed to wave-swash interactions that can enhance net transport rates in either onshore or offshore direction (Weir et al., 2006; Hughes and Moseley, 2007; Masselink et al., 2009; Blenkinsopp et al., 2011). Several detailed numerical models have been developed to investigate the net morphodynamic change by dam-break swash (e.g. Postacchini et al., 2012; Zhu and Dodd, 2013) or swash events composed of multiple bores (Incelli et al., 2016); a recent overview on swash zone morphodynamic models was presented by Briganti et al. (2016).

Although many studies have been dedicated to understanding swash zone 
morphodynamics, most previous experimental studies focused either on detailed sand transport processes at few cross-shore locations, or on bulk statistics of net transport rates in relation to wave conditions. The relation between intra-swash processes and swash-averaged sand transport rates and morphologic change is, to a large extent, still unclear. This especially holds for the more complex swash events that include wave-swash interactions. This lack of process insights ultimately hampers the development of numerical models for sand transport in the swash zone.

Therefore, the present study aims to improve insights into the effects of intra-swash hydrodynamics and sediment transport processes on net bed level change and sand transport rates. The specific research objectives are firstly to study sand suspension and sheet flow layer processes near the shoreline, and relate them to visual observations and measurements of the swash flow. The second objective is to quantify bed level changes at intra-swash and swash-averaged time scales and to relate them to the intra-swash processes. The effects of different types of wave-swash interactions are of particular interest. These processes are studied through experiments in a large-scale wave flume which allows the generation of repeatable swash events. Compared to previous laboratory experiments on this topic (van der Zanden et al., 2015; Alsina et al., 2018), the present study offers more detailed measurements of the sediment exchange between the surf-swash boundary and extends insights on bed level changes and sand transport rates at different time scales (intraswash, swash-event averaged, and averaged over multiple swash events). The experiment is described in Section 2. The overall bed profile evolution is presented in Section 3. Section 4 presents the intra-swash hydrodynamic 
and sediment transport processes, followed by the measured bed level changes and sand transport rates (Section 5). The results are discussed in Section 6 and the main conclusions are presented in Section 7.

\section{Experiments}

\subsection{Experimental set-up}

The experiments were conducted in the large-scale CIEM wave flume at the Universitat Politècnica de Catalunya, Barcelona, Spain. The flume is approximately $100 \mathrm{~m}$ long, $3 \mathrm{~m}$ wide, and $4.5 \mathrm{~m}$ deep. Figure 1 shows the experimental set-up. The water depth $h$ near the wave paddle was $2.50 \mathrm{~m}$. The vertical coordinate $z$ is defined positively upward from the still water level (SWL) and the cross-shore coordinate $x$ is defined positively landward from the initial shoreline, the latter being calculated as the intersection between the SWL and the initial bed profile.

The beach profile consisted of medium sand with a median diameter $D_{50}$ $=0.25 \mathrm{~mm}, 10 \%$ and $90 \%$ cumulative intercepts $D_{10}=0.15 \mathrm{~mm}$ and $D_{90}$ $=0.37 \mathrm{~mm}$, and a measured mean settling velocity $w_{\mathrm{s}}=0.034 \mathrm{~m} / \mathrm{s}$. The initial bed profile followed a 1:15 slope (Figure 1). In order to reduce crossflume flow and bed level asymmetries in the swash zone, the swash zone was divided into three compartments with approximately same widths by means of steel rectangular plates ("dividers") along two cross-shore transects. The $0.70 \mathrm{~m}$ high, $6 \mathrm{~m}$ long dividers were buried approximately $0.40 \mathrm{~m}$ into the initial bed and they extended over $x=3.4$ to $9.4 \mathrm{~m}$. A similar application of dividers to reduce cross-tank bed asymmetry was adopted by Baldock et al. (2017). 


\subsection{Wave conditions}

The waves were generated at intermediate water depth by the wedgetype wave maker. Steering signals for the wave paddle were based on firstorder wave theory. After building the bed profile, 30 min of irregular waves with significant wave height $H_{\mathrm{s}}=0.42 \mathrm{~m}$ and peak period $T_{\mathrm{p}}=4.0 \mathrm{~s}$ were produced in order to compact the bed. The experiment started with this profile (experimental time $t=0$ ).

After this, four 30-min and two 60-min consecutive hydrodynamic runs were generated using bichromatic wave time series, yielding a total experimental duration of 240 min (4 hours). Bichromatic waves result in repeatable swash events, hence allowing for ensemble-averaging in order to increase the accuracy of results, while they produce a similar morphologic development as irregular waves (e.g. Baldock et al., 2011). An erosive and narrow-banded bichromatic wave condition was selected, which was expected (based on previous experiments by Alsina et al., 2018) to result in energetic flow conditions, strong wave-swash interactions, and relatively high cross-shore advection of sediment.

The bichromatic waves in the present experiment had frequencies $f_{1}=$ $0.304 \mathrm{~Hz}$ and $f_{2}=0.236 \mathrm{~Hz}$ and wave heights $H_{1}=H_{2}=0.32 \mathrm{~m}$, corresponding to a fully modulated wave group with group period $T_{\mathrm{gr}}=\frac{1}{f_{1}-f_{2}}=14.8 \mathrm{~s}$ and a mean short wave period $T_{\mathrm{m}}=\frac{2}{f_{1}+f_{2}}=3.7 \mathrm{~s}$.

Furthermore, the phase of the short waves within the groups was modulated at a specified "repeat frequency", which is defined as the frequency at which a short wave phase within the group repeats exactly (Baldock et al., 2000). This phase modulation allows to generate swash events that have the 
same offshore wave height and peak period, but the different timing of the short waves leads to variations in wave-swash interactions. For the present experiment, the repeat period $T_{\mathrm{R}}=2 T_{\mathrm{gr}}$, hence resulting in two alternating wave group induced swash events, termed A and B in what follows.

\subsection{Measurements}

An overview of the instruments is presented in Figure 1 and Table 1. A combination of resistive wave gauges (RWGs), acoustic wave gauges (AWGs), and pressure transducers (PTs) was deployed to measure the water surface elevation $\eta$ at various locations in the flume, covering the deeper section of the flume up to the swash. All measurements of $\eta$ were acquired at a sampling frequency $f_{\mathrm{s}}=40 \mathrm{~Hz}$. The non-linear, weakly dispersive approach by Bonneton et al. (2018) was applied to retrieve $\eta$ from the pressure measurements by the PTs. In the swash zone, the AWGs measured the water surface elevation when the bed is submerged, or the bed level when it is exposed. The measurement accuracy of the RWGs and PTs is estimated to be about 1 $\mathrm{mm}$. The theoretical accuracy of the AWGs is $0.2 \mathrm{~mm}$, except for the AWGs at $x=5.56$ and $6.51 \mathrm{~m}$ which have an accuracy of $0.02 \mathrm{~mm}$ (values provided by the manufacturers of the commercial AWGs).

In order to quantify horizontal pressure gradients, additional measurements of the water pressure at bed level were obtained using three PTs, deployed around $x=1.28 \mathrm{~m}$ and separated by $\Delta x=0.05 \mathrm{~m}$. These PTs were orientated parallel to the bed, and were buried prior to each run such that their top aligned with the local bed level.

The three-component flow velocity was measured at $f_{\mathrm{s}}=100 \mathrm{~Hz}$ using acoustic Doppler velocimeters (ADVs) at five cross-shore locations, deployed 
from the side-walls at a minimum distance of $0.3 \mathrm{~m}$ from the wall. All Nortek ADVs were of a side-looking type and were deployed with a vertical orientation of the ADV stems. This configuration minimizes flow disturbance and facilitates measuring even at relatively shallow water depths. Prior to each experimental run, all ADVs were vertically repositioned to $0.030 \mathrm{~m}$ above the local bed level. The cross-shore velocity $u$ is defined positively landward.

Measurements of suspended sand concentrations were obtained at $f_{\mathrm{s}}=$ $40 \mathrm{~Hz}$ using five optical backscatter sensors (OBSs). The OBSs were deployed from the side-walls at approximately the same locations as the ADVs and were repositioned to $0.030 \mathrm{~m}$ above the local bed before each run. All OBSs were calibrated at UPC for the present sediment, with a replica of the calibration apparatus described by Downing and Beach (1989).

Sand concentrations in the SFL and the local bed level were measured at two cross-shore locations using a conductivity-based concentration measurement system, $\mathrm{CCM}^{+}$(described in detail by van der Zanden et al., 2015). The $\mathrm{CCM}^{+}$system consists of two tanks that are buried into the bed. The tanks contain up to three probes that can be vertically repositioned. The probes enter the SFL from below, in order to minimize flow disturbance, and measure the resistivity of the sediment-water mixture. The resistivity can be translated to a concentration using a linear calibration, based on measurements of the resistivity in the clear water and in the bed before each experimental run. The measurement volume of each probe extends vertically to 1-2 mm. The probes positions are continuously measured and can be controlled with sub-mm accuracy using servomotors in the tanks. The 
$\mathrm{CCM}^{+}$system contains a bed level tracking mode in which the probes are automatically repositioned to the elevation corresponding to the bed-water interface or the middle of the SFL, hence also yielding a direct, continuous measurement of the local bed level (more details are given by van der Zanden et al., 2015).

The two $\mathrm{CCM}^{+}$tanks were deployed near the initial shoreline (Figure 1b). Tank 1 contains a single and a twin probe that consists of two sensors, spaced $1.5 \mathrm{~cm}$ in cross-shore direction. The latter can be used to measure particle velocities in the sheet flow layer through cross-correlation (see McLean et al., 2001, for more details). In the present experiment, the single probe was used to measure the continuous bed level, while the twin probe measured SFL concentrations at various elevations around the evolving bed level. The latter was achieved by adopting the procedure described by van der Zanden et al. (2017), i.e., by alternating between 60 -s intervals in a concentration measurement mode (concentration measurements at varying, prescribed elevations, covering a vertical range of $\pm 15 \mathrm{~mm}$ relative to the bed) and 15-s intervals in the bed level tracking mode. A second $\mathrm{CCM}^{+}$tank with one single probe was buried $1.7 \mathrm{~m}$ offshore from tank 1 . The control settings of the twin probe (tank 1) were also applied for the single probe of tank 2. All $\mathrm{CCM}^{+}$positions and concentrations were sampled at $f_{\mathrm{s}}=1000 \mathrm{~Hz}$. Section 2.4 describes how the SFL concentration field is reconstructed from the concentration and bed level measurements.

The bed profile was measured at the start of the experiment and after each experimental run, using the wheel bottom profiler described in SánchezArcilla and Cáceres (2017). The wheel profiler had $0.01 \mathrm{~m}$ vertical accuracy 
and measured along the center line of the flume with $0.02 \mathrm{~m}$ cross-shore resolution. Visual observations of the shoreline after each run were used to ensure the profile measurements had the appropriate vertical reference relative to the SWL. The maximum run-up and minimum run-down locations were visually observed and noted down for each run. For some experimental runs the swash flow was recorded on video.

\subsection{Data treatment}

All wave gauge and pressure measurements seaward from the shoreline were vertically referenced with respect to the still water level at the start of a run. All AWG measurements were de-spiked. Spectral analysis showed that several AWG signals contained continuous spurious recordings with an amplitude of $0.01 \mathrm{~m}$ and a frequency $f=10 \mathrm{~Hz}$, likely due to an electric distortion in their acquisition unit. These recordings were removed by a lowpass filter with cut-off frequency $f=8 \mathrm{~Hz}$. The AWG measurements in the swash zone were converted into water depths by relating the water surface elevation to the local, evolving bed. The exposed bed levels were obtained from the AWG signal by using a moving minimum with a time window equal to $T_{\mathrm{gr}}$ and were then cubicly interpolated in time to obtain the evolving bed.

Spurious ADV measurements were identified as having a signal amplitude (in digital counts) $<25$ or a correlation value $<50 \%$. These recordings were removed from the time series and not replaced. Phase-averaged velocities were discarded for phase-averaged signal amplitudes $<50$. ADV and OBS measurements were discarded for water depths $h<0.05 \mathrm{~m}$, when the sensors are exposed or very close to the water surface level.

The pressure measurements in the swash, used to measure the pressure 
gradients, were first de-meaned in order to remove any possible bias caused by offsets in alignment with the bed. The measured pressure heads were then converted to an absolute vertical reference by adding the local bed elevation obtained from the bed profile measurements. Finally, the cross-shore pressure gradient at $x=1.28 \mathrm{~m}$ was calculated from the most landward and most seaward PTs (separated by $\Delta x=0.10 \mathrm{~m}$ ) through central differencing.

All hydrodynamic and OBS measurements were phase-averaged following the approach for wave groups that was presented by van der Zanden et al. (2019) and that is shortly summarized here. Slight variations in the timing of the short waves within each repeat cycle may lead to smoothening of the phase-mean when the data are directly phase-averaged over $T_{R}$ (van der Zanden et al., 2019). This effect was reduced by phase-referencing (i.e., determine the zero crossings) and phase-averaging the data for each of the short waves that form a $T_{\mathrm{R}}$ cycle, rather than directly over the full $T_{\mathrm{R}}$ cycle. The phase averages of the short waves were then merged to obtain a phase average at the $T_{\mathrm{R}}$ cycle. Only data of the last two hydrodynamic runs (two hours) were used for phase-averaging, assuming that a quasi-equilibrium morphological equilibrium has established at that time (see Section 3 for the profile evolution, and Alsina et al. $(2016,2018)$ for information on beach profile variability under bichromatic wave conditions). For each run, the first five minutes of data were discarded. The phase averages are time-referenced such that $t / T_{\mathrm{gr}}=0$ corresponds to the arrival of the first wave of wave group A at the location of $\mathrm{CCM}^{+}$tank 2 (unless stated differently).

The $\mathrm{CCM}^{+}$measured concentrations at various elevations around the evolving bed. As a first processing step, the continuous bed level $z_{\text {bed }}(t)$ at the 
locations of both tanks was reconstructed by a temporal cubic interpolation of the direct bed level measurements by the $\mathrm{CCM}^{+}$(i.e., when in bed level tracking mode). This allowed the known probe elevation $z_{\text {probe }}(t)$ with respect to the top of the tank to be vertically referenced with respect to the evolving bed level, yielding a relative probe elevation $z^{\prime}(t)=z_{\text {probe }}(t)-z_{\text {bed }}(t)$. The $\mathrm{CCM}^{+}$concentration measurements $C\left(z^{\prime}, t\right)$ were then phase-averaged and at the same time vertically bin-averaged using a bin size $\Delta z^{\prime}=0.5 \mathrm{~mm}$. This ultimately resulted in phase-averaged concentration profiles $C\left(z^{\prime}, t / T_{\mathrm{gr}}\right)$ in the sheet flow layer (for more details about the $\mathrm{CCM}^{+}$data processing methodology, the reader is referred to van der Zanden et al., 2015, 2017). The $\mathrm{CCM}^{+}$data were averaged over the last two hours of experiments, corresponding to approximately 240 swash repetitions.

Sediment particle velocities in the sheet flow layer were obtained using the cross-correlation method described by McLean et al. (2001). The method estimates particle velocities based on the time lag that a turbulent cloud of particles requires to travel between two sensors aligned in cross-shore direction. In the present study, the high-pass filtered (1 Hz cut-off frequency) concentration measurements by the two sensors of the twin probe were crosscorrelated for time intervals $\Delta t=0.3 \mathrm{~s}$, corresponding to 100 phases in the $T_{\mathrm{R}}$ cycle. The cross-correlation output was phase-averaged and bin-averaged over concentration bins with $\Delta C=0.1 \mathrm{~m}^{3} / \mathrm{m}^{3}$. The averaging over concentration bins facilitates the calculation of particle velocities at different elevations (corresponding to concentration levels) in the sheet flow layer. Finally, the time lag corresponding to the maximum phase-averaged cross-correlation output is used to calculate the phase-averaged particle velocity $u_{\mathrm{p}}(t)$. 


\section{Bed profile evolution}

Figure 2a shows the bed profile evolution during the experiment. The bed profile evolves rapidly during the first $120 \mathrm{~min}$. Prominent morphologic features that are formed include a berm $(x=6-10 \mathrm{~m})$ and a breaker bar (crest at $x=-10 \mathrm{~m}$ ). During these first two hours, the shoreline retreats by $1.8 \mathrm{~m}$. During the remainder of the experiment $(t=120$ to $240 \mathrm{~min})$, the profile rate of change is much lower. The breaker bar and trough move gradually offshore, while the swash berm shows little further development. The shoreline continues to erode (by $0.5 \mathrm{~m}$ ), but with much smaller rates of change than during the first two hours. Based on this morphologic evolution, the bed profile between $t=120$ and $240 \mathrm{~min}$ is considered to be in a quasiequilibrium state in which the bed level change is assumed to have a negligible effect on the hydrodynamic and sediment transport processes of interest.

The net total sand transport rate $q_{\text {tot }}$ can be calculated from the bed profile rate of change $\Delta z_{\mathrm{b}} / \Delta t$ by solving a mass balance equation (Exner equation):

$$
q_{\text {tot }}\left(x_{i}\right)=q_{\text {tot }}\left(x_{i-1}\right)-\int_{x_{i-1}}^{x_{i}} \rho_{\mathrm{s}}(1-p) \frac{\Delta z_{\mathrm{b}}}{\Delta t} \mathrm{~d} x
$$

where $p=0.4$ is the porosity of the loosely packed sand and $\rho_{\mathrm{s}}=2650$ $\mathrm{kg} / \mathrm{m}^{3}$ is the sediment density. Equation 1 is solved numerically, starting from the landward end of the profile where $q_{\text {tot }}=0$. Figure $2 \mathrm{~b}$ shows the mean $q_{\text {tot }}$ for each experimental hour. Net total transport magnitudes are highest in the first hour. During the first hour the swash berm is largely formed by landward transport at $x>0 \mathrm{~m}$ while the seaward transport at $x<0 \mathrm{~m}$ contributes to the breaker bar formation. The transport rates decrease as the 
bed profile evolves. During the last two hours $(120-240 \mathrm{~min})$ the transport at the berm $(x>5 \mathrm{~m})$ is minor, while a gradual, seaward-directed transport persists around the initial shoreline $(x=0 \mathrm{~m})$.

For a more detailed analysis of the bar formation and shoreline evolution during the experiment, the reader is referred to Eichentopf et al. (2019).

\section{Intra-swash hydrodynamics and sand transport processes}

This section presents an overview of the hydrodynamics (Section 4.1), followed by the measurements of sand suspension, sheet flow layer dynamics, and intra-swash sand transport rates (sections 4.2, 4.3, and 4.4, respectively).

\subsection{Hydrodynamics}

\subsubsection{Wave evolution}

In this section the water surface elevation in time and space is studied. The mean variability (averaged over time and over all locations) in phaseensembles of the water surface elevation is $0.006 \mathrm{~m}$ (i.e., $<<H_{1}, H_{2}$ ). This indicates a good repeatability of the generated wave groups and swash events. The wave evolution along the flume is illustrated in Figure 3. Figure 3a-c shows the phase-averaged water surface elevation at three cross-shore locations. In this representation, the time series are phase-referenced such that $t / T_{\mathrm{gr}}$ corresponds to the start of the $T_{\mathrm{R}}$ cycle at each location.

Near the wave paddle $(x=-63.4 \mathrm{~m})$ the two wave groups together consist of approximately seven short waves that are roughly sinusoidal in shape and that are of similar wave period. The significant wave height is similar for both groups, but the timing of the short waves varies slightly. 
At $x=-15.7 \mathrm{~m}$, just before outer wave breaking, the wave group structure has remained similar while the wave height and skewness have increased considerably. In the inner surf zone $(x=-3.4 \mathrm{~m})$, the wave height has decreased due to energy losses at breaking and the short waves have a pitched forward, sawtooth-shape. The seven short waves can still be identified, but the higher waves have shifted forward in phase within the group. This form of amplitude dispersion, termed "wave focusing", occurs at intermediate and shallow water depths and is explained by a higher propagation speed of the short waves that travel at the crest of the long wave (van Dongeren et al., 2007; Tissier et al., 2015; Padilla and Alsina, 2017).

Figure $3 \mathrm{~d}$ shows the cross-shore distribution of the maximum wave height $H_{\max }$, calculated here as the difference between minimum and maximum phase-averaged $\eta$. The wave height is roughly constant over the deeper section of the flume and increases over the sloping bed. Visual observations show that wave breaking occurred at $x=-10 \mathrm{~m}$ for the larger waves and at $-5.5 \mathrm{~m}$ for the smaller waves, which corresponds to the region of decreasing $H_{\text {max }}$.

For the present bichromatic waves, wave shoaling and breaking is expected to not only lead to a transfer of energy to the higher harmonics but also to the group-bound and breakpoint-generated forced long waves (Baldock et al., 2000; Janssen et al., 2003; Lara et al., 2011; Padilla and Alsina, 2017). The energy at short- and long-wave frequencies is examined by decomposing the phase-averaged water surface elevation into a high-frequency $\left(\eta_{\mathrm{hf}}\right)$ and low-frequency $\left(\eta_{\mathrm{lf}}\right)$ component, using an 8th-order Butterworth filter with $0.1 \mathrm{~Hz}$ cut-off frequency. 
Figure 3e shows the root-mean-square (rms) of both components. The low-frequency component $\eta_{\mathrm{If}, \mathrm{rms}}$ increases from the wave paddle up to outer wave breaking, consistent with an energy transfer from the short waves to the bound long wave. The low-frequency wave energy decreases in the surf and swash zones, but not as rapidly as the energy at the short-wave frequencies. As a result, $\eta_{\mathrm{If}, \mathrm{rms}}$ exceeds $\eta_{\mathrm{hf}, \mathrm{rms}}$ around the shoreline and in the swash. A clear pattern of cross-shore modulations is observed for $\eta_{\mathrm{If}, \mathrm{rms}}$, marking the nodes $(x=-22$ and $-3.5 \mathrm{~m})$ and anti-nodes $(x=-32,-11$, and $0.5 \mathrm{~m})$ of a quasi standing wave. This standing wave pattern is highly similar to measurements by Alsina et al. (2016) and is explained by the linear superposition of the incident bound long and outgoing reflected and breakpoint-generated free long waves (Baldock et al., 2000; Baldock, 2006; Padilla and Alsina, 2018).

The energy transfer to long-wave frequencies may be explained by two mechanisms: (i) the nonlinear coupling of primary wave components (LonguetHiggins and Stewart, 1962); (ii) breakpoint generation of the long wave (Symonds et al., 1982). The dominance of either mechanism can be predicted using empirical parameters, e.g., the normalized beach slope (Battjes et al., 2004) or the surf beat similarity parameter (Baldock, 2012). Based on both parameters, the present experiment corresponds to a steep-slope, steep-wave regime in which the breakpoint generation mechanism dominates over the nonlinear growth mechanism.

The propagation of wave groups in the surf and swash regions is further illustrated in Figure 4 which shows the high (Figure 4a) and low frequency (Figure $4 \mathrm{~b}$ ) phase-averaged water surface elevation along the flume as con- 
tour plots. The phasing of the individual waves forming the groups clearly determines the swash events and the degree of interaction between shoreline oscillation and successive arriving waves (next section). The quasi standing pattern of $\eta_{\mathrm{lf}}(t)$ is clearly seen in Figure $4 \mathrm{~b}$, with nodes and anti-nodes corresponding to the descriptions of Figure 3e. Similar patterns of $\eta_{\mathrm{lf}}(t)$ have been observed in previous experimental (Padilla and Alsina, 2018) and numerical (e.g. Brocchini and Peregrine, 1996) studies. The low frequency motion affects the swash motion as the shoreline oscillation correlates positively with $\eta_{\text {lf }}(t)$ and because it affects the short-wave celerity in shallow water (Tissier et al., 2015; Padilla and Alsina, 2017).

\subsubsection{Description of swash events}

The swash events are first qualitatively discussed using the photo series in Figure 5. The top panel shows the water depth at the location of $\mathrm{CCM}^{+}$ tank 1 and includes phase reference to the photos (marks a-j). The photos are snapshots from a video recording, obtained from the upper swash zone facing in seaward direction. The swash dividers are seen in the lower half of each photo. The bottom of the photos corresponds to $x \approx 4 \mathrm{~m}$, the black dashed line marks the location of $\mathrm{CCM}^{+}$tank $1(x=1.28 \mathrm{~m})$. The photos illustrate the stepwise evolution of the swash events:

a) The first bore of swash event $\mathrm{A}$ has just reached the initial shoreline location. Two bores (a small one, followed by a larger one) can be observed just seaward of $\mathrm{CCM}^{+}$tank 1 .

b) The second bore has a higher propagation speed than the first bore, possibly because it travels on the crest of the long wave (see Figure 4). 
The second bore has almost overtaken the first bore and both bores have passed $\mathrm{CCM}^{+}$tank 1 with a minor time delay. The water depth (top panel) increases in two steps, first at $t / T_{\mathrm{gr}}=0.08$ (arrival of the first bore) and then at $t / T_{\mathrm{gr}}=0.13$ (arrival of the second bore). The overtaking of the first bore by the second, termed "wave capture" following Hughes and Moseley (2007), occurs at $x=1.5 \mathrm{~m}$ (just landward of $\mathrm{CCM}^{+}$tank 1). The two merged bores generate a large run-up.

c) In the mid swash (bottom half of photo), the backwash has started and the velocity is seaward directed. A third incident bore propagates towards the swash zone (upper arrow in photo).

d) The third incident bore is retarded by the seaward momentum of the backwash. The incident bore passes the $\mathrm{CCM}^{+}$, but is then fully halted at $x \approx 1.8 \mathrm{~m}$, leading to a stationary bore that is similar to a hydraulic jump ("strong wave-backwash interaction", after Hughes and Moseley, 2007). The photo shows a high suspended sand load in the stationary bore.

e) The stationary bore is washed seaward during the remainder of the backwash stage. A next bore (first bore of event B) is observed in the inner surf zone.

f) The start of swash event B. The first bore in event B has been slowed down by the momentum of the preceding backwash of event A. A second incident bore has almost overtaken the first bore of event B.

g) The second bore of event B overtakes and merges with the first bore. 
This occurs at $x \approx-1 \mathrm{~m}$, which is approximately $2 \mathrm{~m}$ seaward of $\mathrm{CCM}^{+}$tank 1. The merged bore has a steep front, leading to a sudden rise in water depth at the location of $\mathrm{CCM}^{+}$tank 1 (upper panel, $\left.t / T_{\mathrm{gr}}=1.10\right)$.

h) The merged bore produces a run-up that is lower than for event A. A third bore of wave group B is observed in the inner surf zone.

i) The third bore arrives to the swash. The bore has higher momentum than the retreating backwash and it continues to propagate landward ("weak wave-backwash interaction", Hughes and Moseley, 2007), producing a second uprush within swash event B. The run-up is followed by a long, uninterrupted backwash.

j) A fourth, small bore arrives to the swash. The bore has little momentum and dissipates near the initial shoreline (marked by "=" in the photo). The swash front of this bore does not reach $\mathrm{CCM}^{+} \operatorname{tank} 1$. The first bore of event A can be seen in the inner surf zone (marked by arrow).

A more quantitative illustration of the swash events is shown in Figure 6a (AWG measurements). The boundary between the swash zone and the inner surf zone was established from visual observations of the minimum run-down location $(x=-0.9 \mathrm{~m})$. The maximum run-up, produced by events of type A, was visually observed to reach $x=9.9 \mathrm{~m}$, hence the total swash excursion is $10.8 \mathrm{~m}$. Following definitions by Aagaard and Hughes (2006), the lower (>75\% immersion), mid ( $>40,<75 \%$ immersion) and upper $(<40 \%$ immersion) swash zones are distinguished (Figure 6b). 
Figure 6a shows the large uprush generated by the two first bores of event A. The third bore (arriving to the lower swash around $t / T_{\mathrm{gr}}=0.4$ ) does not produce another major uprush event but is instead halted at $x=1.8 \mathrm{~m}$ $\left(t / T_{\mathrm{gr}}=0.6\right)$. Swash event $\mathrm{B}$ generates a first uprush with a maximum location of $x=5.5 \mathrm{~m}$, which is considerably lower than for the uprush by event A $(x=9.9 \mathrm{~m})$. This implies that the incident momentum of the two first bores at the shoreline is higher for event A than for event B. The third incident bore of event $\mathrm{B}$ arrives to the initial shoreline around $t / T_{\mathrm{gr}}=1.25$ and produces another run-up, with a similar maximum location $(x=6.0 \mathrm{~m})$ as the first run-up of this event.

\subsubsection{Flow velocity}

The cross-shore flow velocity $u$ measured by the ADVs at $z-z_{\text {bed }}=0.03$ $\mathrm{m}$ is shown for three cross-shore locations in Figure 6b. For the interpretation it should be noted that fluid velocities in the swash are depth-variable, with boundary layers that can reach up to the water surface (Pintado-Patiño et al., 2015). For the present study, assuming a roughness $k_{s}=3 D_{90}$ (Hughes, 1995), the bed would be classified as hydraulically smooth following Jonsson (1980). For such smooth beds and for similar velocity magnitudes as the present study's, O'Donoghue et al. (2010) observed that swash velocities are approximately depth-uniform above a near-bed layer that reaches up to about $0.02 \mathrm{~m}$. Consequently, the ADV-measured velocities at $z-z_{\text {bed }}=$ $0.03 \mathrm{~m}$ can be considered a reasonable proxy for the depth-averaged velocity. The velocities can be directly related to the water depths, shown as colour contour in the background of Figure 6b.

High landward velocities are observed at the front of event A's uprush 
$\left(t / T_{\mathrm{gr}}=0-0.2\right)$. The velocity at $x=-1.54$ and $0.27 \mathrm{~m}$ increases in two steps, due to the two bores arriving shortly after each other, whereas it increases at once at $x=2.26 \mathrm{~m}$, where the bores have merged. Comparing the maximum velocity at the three cross-shore locations shows that the uprush flow accelerates between $x=-1.54$ and $0.27 \mathrm{~m}$ (inner surf to lower swash), reaching a maximum of $1.6 \mathrm{~m} / \mathrm{s}$, and decelerates towards $x=2.26 \mathrm{~m}$ (lower swash to mid swash).

The backwash flow of event $\mathrm{A}\left(t / T_{\mathrm{gr}}=0.3-0.95\right)$ is strongly cross-shore non-uniform. The backwash flow at $x=2.26 \mathrm{~m}$ increases progressively in magnitude, reaching values up to $-2 \mathrm{~m} / \mathrm{s}$. The seaward-directed velocity at $x=0.27 \mathrm{~m}$ increases after flow reversal $\left(t / T_{\mathrm{gr}}=0.30-0.43\right)$, but then it decreases due to the arrival of the third incident bore that induces the strong wave-backwash interaction. Comparison of the velocity at the three locations indicates the high non-uniformity of the cross-shore flow at this stage of the swash cycle $\left(t / T_{\mathrm{gr}} \approx 0.43\right)$. Velocities at $x=0.27 \mathrm{~m}$ are seaward-directed while the third incident bore passes and continues to propagate landward. This likely marks a strong vertical shear distribution of $u$, with seawarddirected velocities near the bed (as measured by the ADV at $z-z_{\text {bed }}=0.03$ $\mathrm{m}$ ) and landward-directed velocities higher in the water column. Such a vertical structure of the cross-shore flow with seaward- and landward-directed constituents would be consistent with previous measurements of the flow in case of strong wave-backwash interactions (Chen et al., 2016; Pujara et al., $2015 b)$. The remainder of the backwash is characterized by quasi-steady velocities of about $-0.6 \mathrm{~m} / \mathrm{s}$ at $x=0.27 \mathrm{~m}$ and $-1 \mathrm{~m} / \mathrm{s}$ at $x=-1.54 \mathrm{~m}$.

The first uprush of event B (starting at $t / T_{\mathrm{gr}}=0.95$ ) is formed by two 
bores that merge in the inner surf zone. Maximum $u$ during the uprush is approximately $1 \mathrm{~m} / \mathrm{s}$ for each location. The third bore (inducing the weak wave-backwash interaction) arrives at $t / T_{\mathrm{gr}}=1.2-1.3$, just when the backwash stage induced by the first uprush is about to begin, and leads to a short-duration reversal to landward flow of small magnitude. The backwash flow increases gradually in magnitude at $x=2.26 \mathrm{~m}$, while it is quasi-steady at $x=0.27 \mathrm{~m}$.

Comparison of the two events shows that the higher maximum run-up for event $\mathrm{A}$ is explained by a higher uprush velocity and landward momentum flux in the lower swash. The difference in maximum run-up between the two events relates further to the relatively high seaward-directed velocities in the inner surf zone $\left(x=-1.54 \mathrm{~m}, t / T_{\mathrm{gr}}=0.6-0.9\right)$ for event $\mathrm{A}$, which causes stronger retardation of the incident bores of event B. The latter also explains why the two first bores merge further seaward for event B than for event A.

\subsection{Sediment suspension}

Several studies have been dedicated to sediment suspension in the swash zone (e.g., Butt and Russell, 1999; Osborne and Rooker, 1999; Aagaard and Hughes, 2006; Cáceres and Alsina, 2012, 2016). The results in this section serve mainly to provide a coherent view on sand transport processes during the present experiment.

The temporal and cross-shore variation in suspended sand concentration, measured by OBSs at $z-z_{\text {bed }}=0.03 \mathrm{~m}$, is shown in Figure 7 . This figure shows the water depth (Figure 7a), cross-shore velocity (Figure 7b) and suspended sand concentration (Figure 7c) at three cross-shore locations (inner surf, lower swash, and mid swash). The water depth and velocity were 
discussed in the previous sections and are here shown for reference.

The temporal variation in $C$ is relatively small at $x=-1.68 \mathrm{~m}$ (inner surf zone), but it increases progressively towards the lower $(x=0.38 \mathrm{~m})$ and mid $(x=2.36 \mathrm{~m})$ swash zone. Peaks in suspended sand concentration are observed during the uprush of both events, with maximum $C$ being reached shortly after the velocity has reached its maximum. The concentration peak at $x=0.38 \mathrm{~m}$ around $t / T_{\mathrm{gr}}=0.60$, shortly after arrival of the third bore $\left(t / T_{\mathrm{gr}}=0.50\right)$, is attributed to a horizontal influx of suspended sediment from the landward side, where the strong wave-backwash interaction induced by the third bore (at $x=1.8 \mathrm{~m}$ ) drives turbulent mixing and pick-up of sediment from the bed. This explanation is supported by other studies that have addressed the significant effect of strong wave-backwash interactions on sand suspension (Hughes and Moseley, 2007; Cáceres and Alsina, 2012). The peaks in $C$ at $x=2.36 \mathrm{~m}$ around $t / T_{\mathrm{gr}}=0.58$ and at $x=0.38 \mathrm{~m}$ around $t / T_{\mathrm{gr}}=1.75$ are probably related to the high flow velocity during the final backwash stages.

For both events, the suspended sand concentration $C$ varies by up to an order of magnitude between the different cross-shore locations. The maximum $C$ during the uprush increases progressively from the inner surf to the lower swash to the mid swash zone, even though the maximum uprush velocity remains of similar magnitude or even decreases over $x$. This indicates that the high suspended sand concentration at the turbulent swash front is probably not only due to local re-suspension at the front, but in addition, due to landward advection of the suspended load that is kept in suspension. This leads to a progressive increase in the suspended load at the swash front 
as it propagates landward (as also shown by Alsina et al. (2018) for similar swash conditions). Also the confining water depth from inner surf to swash zone may contribute to the increase in $C$.

The uprush concentrations are substantially higher for swash event B, despite generally lower uprush velocities than for event A. This is attributed to the differences in the location of wave capture between events A (wave capture at $x \approx 1.5 \mathrm{~m}$ ) and $\mathrm{B}$ (at $x \approx-1 \mathrm{~m}$ ). The uprush of event $\mathrm{A}$ consists in the lower swash of a small incident bore that precedes the larger, main bore, and which reduces the impact of the main bore on the bed. On the other hand, the uprush of event B consists in the lower swash of a single, relatively large bore that propagates directly over the exposed bed and which is therefore expected to induce high bed shear stresses (Barnes et al., 2009; Sou and Yeh, 2011; Kikkert et al., 2012).

\subsection{Sheet flow dynamics}

\subsubsection{Sheet flow layer concentrations and thickness}

The $\mathrm{CCM}^{+}$concentration measurements in the sheet flow layer (SFL) were phase-averaged and vertically bin-averaged over 218 repeating $T_{\mathrm{R}}$ cycles following the procedures described in Section 2.4. Figure 8 shows the phaseaveraged volumetric concentrations around the swash-averaged bed level, $C\left(z^{\prime}, t / T_{\mathrm{gr}}\right)$, normalized by the concentration in the bed $\left(C_{\mathrm{bed}}=1-p=0.6\right.$ $\mathrm{m}^{3} / \mathrm{m}^{3}$ ) for two phases. These phases were selected as they correspond to well-developed sheet flow layers, hence clearly illustrating the vertical structure of the concentration profile. The measured sand concentrations (white circles) approach an upward concave distribution. Despite the phase- and bin-averaging, the scatter in the data is considerable. This is especially at- 
tributed to the uncertainty in the measurement of $z_{\text {bed }}(t)$, and consequently, in $z^{\prime}(t)$, which is estimated to be $\approx 2-4 \mathrm{~mm}$. Such small variability is sufficient to cause significant scatter in $C\left(z^{\prime}\right)$ distributions over a SFL with $\mathcal{O}(\mathrm{mm}$ to $\mathrm{cm})$ thickness.

In order to reduce any effects of the variability in $C\left(z^{\prime}\right)$ on the estimated SFL thickness, the empirical model for concentration distributions by O'Donoghue and Wright (2004a) is fitted to the data:

$$
C\left(z^{\prime}, t\right)=C_{\text {bed }} \frac{\beta(t)^{\alpha}}{\beta(t)^{\alpha}+\left[z^{\prime}+\delta_{\mathrm{e}}(t)\right]^{\alpha}}
$$

In this equation $\alpha$ and $\beta$ are shape parameters; $\delta_{\mathrm{e}}$ is the SFL erosion depth that defines the bottom boundary of the curve. A fixed value of $\alpha=1.5$ is used for the present study (based on O'Donoghue and Wright, 2004a). Previous measurements of $C\left(z^{\prime}\right)$ in the swash agreed well with Equation 2 (Lanckriet et al., 2014; van der Zanden et al., 2015), which justifies the equation's applicability to the present data. The values for $\beta$ and $\delta_{\mathrm{e}}$ are determined by fitting Equation 2 to the log-transformed concentration measurements using a least-square fitting approach. Similar curve fitting to $\mathrm{CCM}^{+}$measurements in the swash was done by van der Zanden et al. (2015) and Alsina et al. (2018). Their approach is followed closely, except that the concentration measurements and the model were transformed by taking the logarithms prior to fitting. This reduces the bias of the fitted curve to high concentrations (lower SFL) and improves the fit in the upper SFL. The coefficient of determination $\left(r^{2}\right)$ was $0.68 \pm 0.12$ for $\mathrm{CCM}^{+}$tank 1 and $0.82 \pm 0.07$ for tank 2 .

Figure 8 shows the obtained fits (solid line) to the measured concentra- 
tions. The grey circle marks the SFL "pivot point" $z_{\mathrm{p}}$, which is the elevation around which the concentration profile pivots as the SFL grows and decays during a wave or swash cycle and which corresponds approximately to the middle of the sheet flow layer (O'Donoghue and Wright, 2004a). The figure also indicates the SFL thickness $\delta_{\text {s }}$, i.e., the distance between the top and bottom of the SFL, with the top defined as the elevation where $C / C_{\text {bed }}=0.12$ (Dohmen-Janssen and Hanes, 2002).

The SFL concentrations are shown in Figure 9d,e. For reference, the figure includes the local water depths (a), cross-shore pressure gradients (b) and cross-shore velocities (c). The pressure gradients $-\mathrm{d} p / \mathrm{d} x$, computed at $x=$ $1.28 \mathrm{~m}$, are negative ("seaward dipping") during most of the swash cycle, with short-duration positive $-\mathrm{d} p / \mathrm{d} x$ peaks ("landward dipping") during incident bore arrivals. The pressure gradients in positive and negative direction are of similar magnitude and the patterns are consistent with previous observations (Baldock and Hughes, 2006; Othman et al., 2014) and numerical simulations (Torres-Freyermuth et al., 2013). The concentration field in Figure 9d,e represents the fitted concentrations (Equation 2). The white areas in the figure correspond to measurements above the water surface. The white lines mark the bottom and top of the SFL and the black line marks the pivot point elevation. Figure $9 \mathrm{f}$ shows the SFL thickness $\left(\delta_{\mathrm{s}}\right)$ at both locations.

At $x=-0.52 \mathrm{~m}$ (Figure 9d) the concentration field is approximately steady, indicating little SFL development, throughout event A. As soon as the uprush of event B starts $\left(t / T_{\mathrm{gr}}=0.99\right)$, the sheet flow layer grows rapidly, leading to a vertical dilution of the concentration field. As soon as the swash front has passed, the SFL reduces in thickness $\left(t / T_{\mathrm{gr}}=1.05-1.20\right)$. The bed 
remains more or less at rest until the SFL expands and decreases again during the late backwash $\left(t / T_{\mathrm{gr}}=1.8-2.0\right)$. The bed experiences a local erosion during the uprush of event $\mathrm{B}$, as shown by the decreasing pivot elevation $\left(t / T_{\mathrm{gr}}=1.0-1.2\right)$, while it is restored during the late backwash stage $\left(t / T_{\mathrm{gr}}=\right.$ 1.8 - 2.0). These intra-swash bed level changes are explored in Section 5.1.

The SFL behaviour at $x=1.28 \mathrm{~m}$ is more dynamic than at $x=0.52$ $\mathrm{m}$ (Figure 9e,f). At the swash front of both events $\mathrm{A}$ and $\mathrm{B}\left(t / T_{\mathrm{gr}}=0.10\right.$ and 1.05) the SFL grows rapidly, followed by a gradual decrease during the remainder of the uprush. Another large increase in SFL thickness occurs between $t / T_{\mathrm{gr}}=0.67-0.74$. This is shortly after the third incident bore has passed and has interrupted the backwash flow, leading to $u$ close to 0 $\mathrm{m} / \mathrm{s}$ (Figure 9a,c). The initiation of sheet flow can be predicted based on the mobility parameter $\psi=u^{2} /\left[(s-1) g D_{50}\right]$, where $s=2.65(-)$ is the relative sediment density and $g=9.81 \mathrm{~m} / \mathrm{s}^{2}$ is the gravitational acceleration. Following van Rijn (2007), the initiation of sheet flow is expected for $\psi>250$, which corresponds for the present sediment to $u>1 \mathrm{~m} / \mathrm{s}$. Consequently, it is unlikely that the observed low velocity magnitudes induce sufficiently high bed shear stresses to mobilize the sand and explain the growth in SFL thickness. Instead, the increase is likely due to a horizontal influx of sediment originating from landward locations: this sediment is mobilized by the strong wave-backwash interaction at $x=1.8 \mathrm{~m}$ (about $0.5 \mathrm{~m}$ landward of these $\mathrm{CCM}^{+}$observations) at $t / T_{\mathrm{gr}}=0.6$; seaward advection of the sheet load drives the observed increase in $\delta_{\mathrm{s}}$ at $x=1.28 \mathrm{~m}$ during $t / T_{\mathrm{gr}}=0.67-0.74$. The latter explanation is supported by observations of van der Zanden et al. (2015) that revealed the significant mobilization of sediment as sheet load by 
strong wave-backwash interactions.

At both locations, the uprush of event B mobilizes more sediment as sheet flow than event A, even though uprush velocities are of similar magnitude. Note that also the suspended sand concentration was substantially higher for the uprush of event B than for event A. Both results indicate a larger sediment mobilization for uprush B, which is explained by the structure of the uprush: a large bore preceded by a small bore for event A, a large "merged" bore propagating over an exposed bed for event B. The direct impact on the bed is expected to be higher for event B (as also addressed in Section 4.2).

Comparison of these two lower swash zone locations shows that the uprush SFL thickness is greater at $x=1.28 \mathrm{~m}$ than at $x=-0.52 \mathrm{~m}$, despite similar uprush velocity. This could be explained by landward advection of the mobilized sediment in the SFL, leading to a gradually increasing sheet load at the propagating swash front. Another explanation could be that the turbulent energy, which has been suggested to contribute significantly to SFL development (Lanckriet and Puleo, 2015), increases from $x=-0.52 \mathrm{~m}$ to $x=1.28 \mathrm{~m}$.

Comparison of Figure $9 \mathrm{~b}$ and e does not reveal any evident relation between the SFL behaviour and the measured cross-shore pressure gradients at $x=1.28 \mathrm{~m}$. The peaks of the pressure gradients during the two uprush events $\mathrm{A}$ and $\mathrm{B}$ are of similar magnitude and do not explain the differences in SFL thickness. The peaks of the positive pressure gradient during the third bore arrival within each event $\left(t / T_{\mathrm{gr}}=0.54\right.$ and 1.30$)$ induce no evident SFL response. Relations between the seaward-dipping pressure gradients (negative $-\mathrm{d} p / \mathrm{d} x)$ and $\delta_{\mathrm{s}}$ are also not evident. This suggests that pressure gradient 
forces are small and that the SFL growth is primarily driven by shear stresses and bore turbulence. The processes governing SFL development are further addressed in the Discussion (Section 6).

\subsubsection{Particle velocities}

The sand particle velocities in the sheet flow layer, $u_{\mathrm{p}}$, were obtained from the concentration measurements using the cross-correlation technique by McLean et al. (2001), as explained in Section 2.4. The $u_{\mathrm{p}}$ measurements were obtained for different concentration bins. The $u_{\mathrm{p}}$ measurements in the lower SFL were somewhat noisy, likely due to the number of swash repeats being too low for sufficient statistical convergence of the averaged crosscorrelations. Therefore, the analysis focuses here on the $u_{\mathrm{p}}$ measurements obtained in the upper sheet flow layer corresponding to the concentration range $C / C_{\text {bed }}=0-0.2$. These velocities were derived from measurements over approximately $60 T_{\mathrm{R}}$ cycle repeats. Recall that particle velocities were only measured by $\mathrm{CCM}^{+} \operatorname{tank} 1$, at $x=1.28 \mathrm{~m}$. Figure $10 \mathrm{~b}$ shows the $u_{\mathrm{p}}$ measurements (circles), together with the ADV measurements of $u$ at $z-z_{\mathrm{bed}}=0.03 \mathrm{~m}$ (solid line). Particle velocities were generally only measured when the SFL is sufficiently developed, primarily during high landward (early uprush) or seaward (mid backwash) free-stream velocity.

During the early uprush stages $\left(t / T_{\mathrm{gr}}=0.1-0.25\right.$ and $\left.1.05-1.15\right)$ the particle velocities in the SFL amount, on average, to $80-90 \%$ of the ADV velocity. This suggests relatively high $u$ up to close distance from the bed and inside the SFL. Such approximately depth-uniform $u$ at the leading edge of the uprush would be consistent with previous observations and can be explained by a limited time for boundary layer development at this lower 
swash location (Kikkert et al., 2013) and by the turbulence that is produced upon wave capture and that leads to strong vertical mixing of momentum (Chen et al., 2016). On the other hand, $u_{\mathrm{p}}$ during the mid backwash stages $\left(t / T_{\mathrm{gr}}=0.45-0.55\right.$ and $\left.1.55-1.75\right)$ amounts to $50-60 \%$ of the ADV velocity. These values are more consistent with SFL observations in tunnels (McLean et al., 2001) and in wave flumes (Dohmen-Janssen and Hanes, 2002; van der Zanden et al., 2017) and suggest a well developed shear layer, consistent with other observations and numerical simulations of the quasi-steady backwash (Sou and Yeh, 2011; Kikkert et al., 2013; Pintado-Patiño et al., 2015).

During the arrival of the third bore for event $\mathrm{A}$ (around $t / T_{\mathrm{gr}}=0.75$ ) the ADV velocity decreases to nearly $0 \mathrm{~m} / \mathrm{s}$, but the $u_{\mathrm{p}}$ measurements indicate that velocities in the SFL remain seaward directed and are of considerable magnitude $(-0.5$ to $-0.7 \mathrm{~m} / \mathrm{s})$. This reaffirms the occurrence of multi-directional velocity over depth (see Section 4.1.3) and is consistent with other measurements of simultaneous seaward near-bed flow and landward free-stream flow in case of strong wave-backwash interactions (Pujara et al., 2015b; Chen et al., 2016). The $\mathrm{CCM}^{+}$measures $u_{\mathrm{p}}$ also during the final backwash stages, when the ADV is exposed and the transport is confined to thin swash lenses. During event A, $u_{\mathrm{p}}$ increases progressively in seaward direction during the final, uninterrupted backwash $\left(t / T_{\mathrm{gr}}=0.80-1.00\right)$. Event B reveals a similar gradual increase $\left(t / T_{\mathrm{gr}}=1.55-1.70\right)$ that is followed by a gradual decrease during the very final stage of the backwash $\left(t / T_{\mathrm{gr}}=1.70-1.95\right)$ when the bed becomes exposed. 


\subsection{Sand transport rates}

\subsubsection{Calculations and assumptions}

The intra-swash sand transport rates were estimated at the location of $\mathrm{CCM}^{+}$tank $1(x=1.28 \mathrm{~m})$. Of specific interest are the temporal variation of transport rates and the relative contributions of suspended and sheet flow transport. These transport rates were not directly measured and their quantification relies on assumptions on the vertical distributions of velocity and concentration in the sheet flow and suspended layers, as explained in what follows.

The depth-integrated sheet flow layer and suspended sand transport rates, $q_{\mathrm{sfl}}$ and $q_{\mathrm{susp}}$, are defined as:

$$
q_{\mathrm{sfl}}=\int_{0}^{\delta_{\mathrm{s}}} u(\zeta) C(\zeta) \mathrm{d} \zeta
$$

and

$$
q_{\text {susp }}=\int_{\delta_{\mathrm{s}}}^{h} u(\zeta) C(\zeta) \mathrm{d} \zeta=\gamma \hat{u} \hat{C} h
$$

where $\zeta=z^{\prime}-\delta_{\mathrm{e}}(t)$ is the height relative to the bottom of the sheet

flow layer denoted by the erosion depth $\delta_{\mathrm{e}} ; \hat{u}$ and $\hat{C}$ are the depth-averaged velocity and concentration, respectively; and $\gamma$ is a shape coefficient.

To calculate $q_{\text {susp }}$, it is assumed that the depth-averaged velocity is reasonably approximated by the ADV measurements at $z-z_{\text {bed }}=0.03 \mathrm{~m}$, i.e., $\hat{u}=u(0.03 \mathrm{~m})$. This assumption was justified in Section 4.1.3 on the basis of velocity distributions observed over hydraulically smooth beds in other swash studies. Note that for depth-uniform velocity, the shape coefficient $\gamma=1$ 
Suspended sand concentrations in the swash tend to follow an exponential distribution (Masselink et al., 2005):

$$
C(\zeta)=C_{\mathrm{r}} \exp (-\zeta / l), \quad \delta_{\mathrm{s}} \leq \zeta \leq h
$$

where $C_{\mathrm{r}}$ is a reference concentration and $l$ is a mixing length. Here, the exponential distribution is assumed to start at the top of the sheet flow layer. At this elevation $\left(\zeta=\delta_{s}\right), C=C_{\mathrm{r}}=0.12 C_{\text {bed }}$. In order for Equation 5 to fit to the OBS-measured concentration $C_{\mathrm{OBS}}$, it can be shown that the mixing length should equal:

$$
l=\frac{\zeta_{\mathrm{OBS}}}{\ln \left(C_{\mathrm{r}} / C_{\mathrm{OBS}}\right)}
$$

In which $\zeta_{\mathrm{OBS}}=0.03+\delta_{\mathrm{e}}$ is the height of the OBS relative to the bottom of the sheet flow layer. Depth-integration of Equation 5 from $\zeta=\delta_{\mathrm{s}}$ to $h$ yields the following expression for $\hat{C}$ :

$$
\hat{C}=\frac{C_{\mathrm{OBS}} l}{h-\delta_{\mathrm{s}}}\left[\exp \left(-\delta_{\mathrm{s}} / l\right)-\exp (-h / l)\right]
$$

Figure 10c shows $C_{\mathrm{OBS}}$ and $\hat{C}$, calculated through Equations 6 and 7 . On average, $\hat{C} \approx 1.2 C_{\text {OBS }}$.

The sand flux distribution in the sheet flow layer was calculated by multiplying the concentration distribution obtained through Equation 2 with an empirical distribution for the particle velocity. The vertical profile of particle velocities in the sheet flow layer is generally considered to follow a power-form (e.g. Wilson, 1966; Sumer et al., 1996): 


$$
u_{\mathrm{p}}(\zeta)=u_{\mathrm{p}}\left(\delta_{\mathrm{s}}\right)\left(\frac{\zeta}{\delta_{\mathrm{s}}}\right)^{n}
$$

where $u_{\mathrm{p}}\left(\delta_{\mathrm{s}}\right)$ is the particle velocity at the top of the sheet flow layer; $n$ is an empirical shape factor. Values proposed for $n$ are in the range of 0.5 to 1 (Wilson, 1966; Sumer et al., 1996; Wang and Yu, 2007; Puleo et al., 2016, 2017); $n=0.75$ following Sumer et al. (1996) was adopted in the present study. The particle velocity at the top of the sheet flow layer was directly measured by the $\mathrm{CCM}^{+}$. Figure $11 \mathrm{~b}$ shows the resulting $u_{\mathrm{p}}$ distribution.

An example of the flux distribution $u C$ in the sheet flow layer is shown in Figure 11c. The flux increases strongly within the first few $\mathrm{mm}$ from the bed, reaches a maximum just below the pivot point, and then decreases gradually upward. This vertical distribution is consistent with direct measurements of the sheet flow flux in oscillatory flow tunnels (e.g. O'Donoghue and Wright, 2004b), in wave flumes under non-breaking and breaking waves (e.g. Schretlen, 2012; Fromant et al., 2018), and in dam-break swash (e.g. Wu et al., 2016).

The uncertainty associated with the quantification of the velocity and concentration profiles is estimated to be $30 \%$, summing up to an uncertainty of $40-50 \%$ for $q_{\text {susp }}$ and $q_{\text {sfl }}$. Although the uncertainty is considerable, it will be shown that the transport rates vary by up to a factor 10 in magnitude during a swash event. Hence, the results are considered sufficiently accurate for the analysis of the temporal variation of transport rates and of the relative importance of $q_{\text {susp }}$ and $q_{\text {sfl }}$. 


\subsubsection{Intra-swash time variation of sand transport rates}

The depth-integrated suspended and sheet flow transport rates are shown in Figure 10e. For reference, the depth-averaged suspended sand concentration and the SFL thickness are shown in Figure 10c-d. Both parameters follow a similar distribution in time.

Figure 10e shows that both transport modes are generally of similar magnitude, consistent with previous observations in field (Horn and Mason, 1994) and laboratory (Ruju et al., 2016; Puleo et al., 2016) swash. However, during instants of intense sheet flow (around $t / T_{\mathrm{gr}}=0.75$ and $t / T_{\mathrm{gr}}=1.1$ ), $q_{\mathrm{sfl}}$ can exceed $q_{\text {susp }}$ by up to a factor five.

The uprush stages are characterized by relatively high landward-directed $q_{\text {susp }}$ and $q_{\text {sfl }}$. The sheet flow transport dominates during the uprush, with $q_{\text {sfl }}$ that exceeds $q_{\text {susp }}$ by up to a factor two (event A) to five (event B). This differs from previous estimates in the lab that suggested a dominance of $q_{\text {susp }}$ during the uprush (Ruju et al., 2016; Puleo et al., 2016). Such differences may relate to strong variations of the bore impact on the bed depending on wave conditions, cross-shore location, and sediment characteristics. For instance, the study by Puleo et al. (2016) involved monochromatic waves, hence the kinematics of the uprush bores may differ substantially from the present study's, in which wave capture during the uprush occurs during both events. In addition, the studies by Puleo et al. (2016) and Ruju et al. (2016) both involved coarse sand whereas medium sand was used in the present study. This difference in grain size leads to direct differences in the onset of sheet flow, but also affects the hydrodynamic conditions in the swash, since a coarser sand bed corresponds to steeper foreslopes and, consequently, more 
reflective swash conditions.

During the early and mid backwash stages $\left(t / T_{\mathrm{gr}}=0.45-0.80\right.$ and $1.45-$ 1.70) both transport modes are seaward-directed and $q_{\text {susp }}$ tends to dominate. An exception is formed during the strong wave-backwash interaction within event $\mathrm{A}\left(t / T_{\mathrm{gr}}=0.70-0.80\right)$ : during this stage, the increase in SFL thickness in combination with the seaward-directed flow in the SFL leads to a large seaward-directed peak in $q_{\mathrm{sfl}}$, while the suspended sand transport reduces to nearly 0 because of the low velocities higher in the water column. During the late backwash stages $\left(t / T_{\mathrm{gr}}=0.80-1.05\right.$ and $\left.1.80-1.95\right), q_{\mathrm{susp}}$ could not be measured but $q_{\mathrm{sfl}}$ is likely dominant due to the small water depths (Masselink and Puleo, 2006).

\section{Bed level changes and net transport rates}

\subsection{Intra-swash bed level changes}

The intra-swash bed level changes already appeared in Section 4.3, but are explored in more detail in the present section. Figure 12c shows the intra-swash bed level changes measured by the two $\mathrm{CCM}^{+}$tanks. The bed level is here approximated by the sheet flow layer pivot point.

The bed at $x=-0.52 \mathrm{~m}$ (red line) remains approximately steady during event A. Apparently, cross-shore transport gradients are not steep enough to promote significant bed level changes. During event B, the bed drops by about $4 \mathrm{~mm}$ during the uprush $\left(t / T_{\mathrm{gr}}=1.0-1.1\right)$ and it recovers during the mid to late backwash $\left(t / T_{\mathrm{gr}}=1.7-2.0\right)$. A stronger bed level variation is revealed at $x=1.28 \mathrm{~m}$ (blue line). The first uprush event leads to a bed erosion of about $8 \mathrm{~mm}\left(t / T_{\mathrm{gr}}=0.1-0.2\right.$, marked I). During the backwash, 
the bed level accretes in two steps (during $t / T_{\mathrm{gr}}=0.5-0.6$ and $0.7-0.8$, marked II and III). The total accretion by events II and III is approximately $16 \mathrm{~mm}$. The uprush of event $\mathrm{B}\left(t / T_{\mathrm{gr}}=1.05-1.15\right.$, marked IV) leads to a rapid erosion of approximately $7 \mathrm{~mm}$ at $x=1.28 \mathrm{~m}$. This erosion rate is similar to that observed for event A. During the remainder of event B the bed at $x=1.28 \mathrm{~m}$ remains relatively stable with slight accretion during the backwash.

Note that only a fraction of this eroded mass is stored locally in the water column: estimates of the depth-integrated suspended load reach maximum values up to $2 \mathrm{~kg} / \mathrm{m}^{2}$, which corresponds to a bed level change of $1.3 \mathrm{~mm}$. Consequently, the bed level changes are not mainly due to changes in storage as suspended load, but instead, to cross-shore gradients in $q_{\text {sfl }}$ and $q_{\text {susp }}$. Although both transport modes are likely to contribute, the transport in the SFL is expected to be the most significant contributor to the bed level changes because $q_{\mathrm{sfl}}(t)>q_{\text {susp }}(t)$ and because the $\mathrm{CCM}^{+}$measurements show that the SFL dynamics in the lower swash alter rapidly with cross-shore distance.

Hence, the erosion events I and IV (Figure 12c) during the early uprush stages are explained by an increasing landward transport rate at the swash front as the bore propagates through the swash. The increasing suspended sand concentration and SFL thickness at the swash front with cross-shore distance (Sections 4.2 and 4.3) support this. The landward advected sand is expected to be temporarily deposited in the mid/upper swash at the late uprush phase, and then (partly) transported back in seaward direction during the backwash as seaward velocities increase. Experimental evidence for this explanation was given by Alsina et al. (2018) for similar swash conditions, 
by means of simultaneous $\mathrm{CCM}^{+}$measurements in the lower and mid swash zones.

The stepwise increase in bed level at $x=1.28 \mathrm{~m}$ (accretion events II and III) for swash event A relates to the altering of the backwash flow by the third incident bore. The backwash induced by the first run-up of event A has high seaward momentum in the mid swash and is at those locations expected to mobilize considerable amounts of sediment. The backwash is interrupted by the third incident bore $\left(t / T_{\mathrm{gr}}=0.52\right)$, which enforces settling out of suspended sediment grains and reduces the seaward-directed sheet flow transport, hence promoting local accretion (accretion event II). This bore subsequently leads to a strong wave-backwash interaction that promotes the turbulent mobilization of sediment at $x \approx 1.8 \mathrm{~m}$, which is advected seaward and deposited around the $\mathrm{CCM}^{+}$location (accretion event III). The strong bed level accretion (16 $\mathrm{mm}$ in total for events II and III) shows that the transport associated with this backwash is highly cross-shore non-uniform, with large changes in transport rates within $\mathcal{O}(0.1$ to $1 \mathrm{~m})$ of cross-shore distance.

The backwash during swash event B hardly induces bed level changes in the lower swash. This is explained firstly by the lower momentum of this backwash, hence leading to less mobilization of sand grains in the mid swash. Secondly, the absence of any wave-swash interactions during the backwash stage leads to a relatively uniform backwash flow in the lower swash and transport gradients are expected to be low.

Magnitudes of bed level changes at $x=-0.52 \mathrm{~m}$ (near transition inner surf to lower swash zone) are considerably lower than at $x=1.28 \mathrm{~m}$ (near 
transition lower to mid swash zone). This is consistent with observations of suspended sand concentrations and SFL thickness, which also showed significantly less sediment mobilization at $x=-0.52 \mathrm{~m}$. The observed bed level changes suggest that, at intra-swash time scale, a considerable amount of sediment is transported within the swash zone, but that the sediment exchange between the swash and inner surf zones is weak in the present study. Note that the present results complement the observations by Alsina et al. (2018), who observed for similar wave conditions a strong intra-swash sediment exchange between the lower and mid to higher swash zones (the sediment exchange with the inner surf zone was not addressed in that study).

\subsection{Swash-averaged bed level changes}

The net (time-integrated) bed level changes induced by swash events A and $\mathrm{B}$ were measured in the lower to upper swash by the conductivity-based $\mathrm{CCM}^{+}$sensors (at two cross-shore locations) and the acoustic wave gauges (AWGs, seven locations). The AWG bed measurements were obtained during intervals of bed exposure. Recall that a moving minimum with time window equal to $T_{\text {gr }}$ was applied to obtain the water depth $h$ from the AWG measurements (see Section 2.4). For the present analysis, the time window was increased to $T_{\mathrm{R}}=2 T_{\mathrm{gr}}$. In this way, the overall bed evolution trend at time scales $\geq T_{\mathrm{R}}$ is filtered out, but net bed level changes by single events $\mathrm{A}$ and $\mathrm{B}$ are preserved in the time series. This bed level detection technique has been applied previously to laboratory swash measurements (Alsina et al., 2012; Cáceres and Alsina, 2012).

To illustrate the technique, Figure 13 shows an example of the phaseaveraged AWG time series, where distinction is made between the identified 
bed levels (brown circles) and water surface elevation (blue line). These bed levels were obtained from the phase-averaged water depths as $h<0.003 \mathrm{~m}$. The time series in Figure 13 were vertically referenced with respect to the mean bed level over both events A and B. The figure shows that the bed level alters after each swash event, with net erosion induced by event $\mathrm{A}$ and net accretion by event $\mathrm{B}$ at this location $(x=3.5 \mathrm{~m})$. The phase-averaged bed level measurements were used to calculate the net bed level change by events A and B at each AWG cross-shore location. Subsequently, the bed level change at time scales $>T_{\mathrm{R}}$, obtained from the bed profile measurements, was added.

Figure 14a shows the bed level changes by events A (blue) and B (red) and the total bed level change by a full repeat cycle (i.e., events $\mathrm{A}$ and $\mathrm{B}$ combined; black dashed line). The circles and squares mark the bed level change measurements by AWG, which could be obtained for $x \geq 0.47 \mathrm{~m}$. Further seaward, the bed was not fully exposed after each backwash. The crosses represent the measurements by the $\mathrm{CCM}^{+}$at two locations. The good agreement between the collocated $\mathrm{CCM}^{+}$and AWG measurements at $x=1.28 \mathrm{~m}$ supports the adopted approach. The dashed blue and red lines represent a cubic interpolation of the bed level measurements.

The results show a strong cross-shore variation in net bed level change. Swash event A leads to net erosion in the mid swash and accretion in the lower and upper swash zones. Patterns for event B are nearly the exact opposite of event A. The net total bed level change (black dashed line) is the small difference between the bed change by both events. The latter implies that the bed profile is in a "dynamic quasi-equilibrium", where each 
single event induces significant morphodynamic change, but where the rate of change over multiple events is minor. Event A induces net accretion in the upper swash, associated with the high run-up of this event that stores sediment at the beach. The bed level in the upper swash decreases slightly during event $\mathrm{B}$, even though the maximum run-up does not reach further than $x \approx 6 \mathrm{~m}$. The decrease in bed level is either due to seaward transport in very thin water films, or due to compaction of the bed as the beach drains. Largest bed level changes are observed in the lower swash, likely due to the occurrence of wave-swash interactions (further addressed in next section). These results are consistent with field measurements by Blenkinsopp et al. (2011), who also observed largest bed level changes in the lower swash.

\subsection{Net sand transport rate by single and multiple swash events}

The net bed level changes can be used to quantify the net sand transport over both events $\mathrm{A}$ and $\mathrm{B}$. This was done by solving the sediment mass balance (Equation 1), starting from the landward boundary, using the cubic interpolated bed changes (dashed line in Figure 14a). The obtained net total sand transport rates $q_{\text {tot }}$ for the two events are shown in Figure 14b (solid lines).

In the lower swash near the run-down $(x<1.1 \mathrm{~m})$, event $\mathrm{A}$ induces net landward and event B induces net seaward transport. This may be explained in terms of velocity variations, as event $\mathrm{A}$ is at these locations characterized by relatively high uprush velocities and B by relatively high backwash velocities. Slightly landward $(x>1.1 \mathrm{~m})$, near the transition from lower to mid swash, $q_{\text {tot }}$ changes sign and the cross-shore transport gradients $\mathrm{d} q_{\text {tot }} / \mathrm{d} x$ reach a maximum. This likely relates to the occurrence of various 
types of wave-swash interactions that have a large effect on the local flow conditions. At the location of $\mathrm{CCM}^{+} \operatorname{tank} 1(x=1.28 \mathrm{~m})$ the net transport is seaward for event A and landward for event B. This is qualitatively consistent with the observations of $q_{\mathrm{susp}}(t)$ and $q_{\mathrm{sfl}}(t)$ (Section 4.4) that showed high seaward transport during the backwash of event A (associated with the strong wave-backwash interaction) and high landward transport during the uprush of event B (associated with the merged bore propagating over the exposed bed). Maximum seaward $q_{\text {tot }}$ for event A occurs in the mid swash, landward from the location of the strong wave-backwash interaction for this event $(x=1.8 \mathrm{~m})$. This implies that this wave-backwash interaction, although mobilizing significant amounts of sediment, does not enhance the net seaward transport - on the contrary, because it halts the backwash, it reduces the seaward transport of sediment in the lower swash.

In the mid swash, event A generates net seaward transport. This likely relates to the relatively long, uninterrupted backwash for this event that produces high seaward velocity. Maximum net seaward transport is observed at $x=2.1 \mathrm{~m}$, landward from the strong wave-backwash interaction. The transport for event $\mathrm{B}$ is landward in the mid swash which may relate to the relatively high landward transport during the uprush (see also OBS and $\mathrm{CCM}^{+}$ measurements) due to wave capture in the lower swash and the onshore advection of sediment as suspended and sheet load. In the upper swash, event A leads to net onshore transport as the large run-up advects sediment landward and stores it at the berm. The net seaward transport for event B may be physical and contained in very thin swash lenses, or an artifact of the compacting bed as the upper swash is drained. 
Several studies have suggested that swash morphodynamics are driven by the combination of (1) the sediment that is mobilized within the swash zone and redistributed across the swash and (2) the sediment that is "premobilized" in the inner surf zone and that is imported/exported at the seaward boundary of the swash (Jackson et al., 2004; Pritchard and Hogg, 2005; Alsina et al., 2009). The importance of the pre-mobilized sand in the present study can be studied by comparing the transport rates near the run-down location with those observed along the swash zone. Figure 14b shows that at $x=-0.5 \mathrm{~m}, q_{\mathrm{tot}}=+0.17 \mathrm{~kg} / \mathrm{ms}$ for event A and $q_{\mathrm{tot}}=-0.29 \mathrm{~kg} / \mathrm{ms}$ for event B. Integrated over a swash event, these values correspond to a net sediment import from surf to swash of $2.5 \mathrm{~kg} / \mathrm{m}$ for event A and a net export of $4.3 \mathrm{~kg} / \mathrm{m}$ for event B. Transport rates increase by up to a factor four in magnitude between the run-down location to the mid swash zone. This implies that the net bed level changes by events A and B are largely due to a cross-shore redistribution of sediment within the swash, with a smaller (but not negligible) contribution of the sand exchanged with the inner surf zone.

Finally, the transport rates averaged over both events, i.e., at the repeat frequency, is analysed (Figure 14b, dashed black line). Similar to the bed level changes, the alternating swash events $\mathrm{A}$ and $\mathrm{B}$ generate $q_{\mathrm{tot}}$ that is at each cross-shore location of similar magnitude but opposite sign. Consequently, the net transport over the repeat cycle at each location is the small difference between large landward or seaward transport rates by a single event. The transport over the repeat cycle is generally seaward directed, consistent with a gradual erosion of the beach. Averaged over both events, the transport rate at the surf-swash boundary is high relative to the transport rates in the 
mid swash. This implies that at longer time scales, the sediment exchange between surf and swash zone becomes increasingly significant for swash zone morphodynamics.

The results show that the significance of the transport across the surfswash boundary for the overall swash zone morphodynamics depends strongly on the time scale of interest (intra-swash, swash-averaged over single events, or averaged over multiple events). Section 6.4 reflects further on this issue.

\section{Discussion}

\subsection{Experiments}

Due to the non-uniformity of the flow and sand transport in the swash, transport processes and net transport rates can vary significantly within short cross-shore distance, especially in the lower swash region where various types of wave-swash interactions occur. Measurements in the present study cover the swash zone with relatively high spatial coverage compared to previous studies. Nevertheless, the flow non-uniformity and the advective cross-shore influx as suspended and sheet load from adjacent locations complicates the interpretation of sand transport physics in the swash, which are not at all governed by purely local hydrodynamic forcing. Consequently, the interpretation of the governing processes based on few local measurements proves to be difficult and subject to conjecturing. Future studies may therefore be aimed at obtaining an even higher spatial coverage of flow velocity, suspended sand concentration, and sheet flow measurements across the inner surf to upper swash zone. In terms of net bed level measurements and transport rates by AWGs, the limited spatial coverage of measurements $(\Delta x \approx 1$ 
$\mathrm{m}$ ) required a spatial interpolation that inherently leads to smoothening of the transport rates. This could not be overcome with the instruments available for the present study. However, techniques to measure the exposed bed level with high spatial coverage and vertical accuracy are available, e.g. LIDAR (Blenkinsopp et al., 2010; Almeida et al., 2015) or stereoscopic imaging (Astruc et al., 2012), for future studies.

\subsection{Insights for numerical modeling of sheet flow transport in the swash}

Consistent with previous swash observations (e.g., Masselink et al., 2005), sheet flow occurred especially during the early uprush and mid/late backwash stages. The sheet flow layer (SFL) reaches thicknesses up to $\delta_{\mathrm{s}}=30 \mathrm{~mm}$, or $\delta_{\mathrm{s}} / D_{50}=120$. Although such thicknesses are similar to previous observations in the swash (e.g., Lanckriet and Puleo, 2015; van der Zanden et al., 2015; Alsina et al., 2018), they are relatively high (given the measured velocity) in comparison to previous medium-sand sheet flow observations, e.g. in oscillatory flow tunnels (Ribberink and Al-Salem, 1995; Hassan and Ribberink, 2005) and under non-breaking waves (Dohmen-Janssen and Hanes, 2002; Schretlen, 2012; van der Zanden et al., 2017). This reaffirms that the relation between free-stream velocity and SFL dynamics in the swash differs from that for non-breaking waves, and that additional processes contribute to SFL growth (see e.g. Lanckriet and Puleo, 2015). The present measurements do not reveal any evidence for cross-shore pressure gradient effects on SFL growth. Hence, the results do not reaffirm previous studies that suggested significant effects of the cross-shore pressure gradient on SFL thickness (Lanckriet and Puleo, 2015), but rather support the results by (Othman et al., 2014) who found minor significance for pressure gradient effects on the 
transport of fine to medium sand in the swash. The large SFL thickness during the uprush may relate to bore turbulence (Lanckriet and Puleo, 2015) and/or a high bed shear stress at the leading edge of the swash due to flow convergence and limited time for boundary layer development (Barnes et al., 2009; Kikkert et al., 2012). In addition, the SFL measurements reaffirm the significance of cross-shore sheet load advection and wave-swash interactions, consistent with earlier observations for narrow-banded erosive swash events (van der Zanden et al., 2015; Alsina et al., 2018).

The significance of sediment advection implies that numerical models for sand transport in the swash should best use advection-diffusion type models, instead of the more common "local" empirical bedload transport models, to resolve the transport in the sheet flow layer. Although several studies have developed 1DV advection-diffusion approaches to simulate sheet flow dynamics in tunnels and under non-breaking waves (Li and Davies, 2001; Holmedal et al., 2004; Kranenburg et al., 2013; Caliskan and Fuhrman, 2017), to the authors knowledge, advection-diffusion models have never been applied to the (2DV) sheet flow transport in the swash. The results in the present study show remarkable similarity in terms of the spatial and temporal variation of suspended sand concentration and sheet flow layer thickness, which suggests that suspension and sheet flow are governed by similar hydrodynamic forcing processes. This implies that a total load approach for the combined sheet load and suspended load may also be well suitable for the swash. Twophase approaches (e.g., Bakhtyar et al., 2010) can also be used to simulate the advection-diffusion of sand as sheet flow, but are generally much more computationally expensive. 


\subsection{Effects of wave-swash interactions on sand transport}

Wave-swash interactions have a strong effect on sand transport processes in the present study, consistent with earlier observations that address the roles of wave-swash interactions on sand suspension (Hughes and Moseley, 2007; Cáceres and Alsina, 2012) and on sheet flow dynamics (Alsina et al., 2018). The key swash interactions in the present study are the wave capture for both events and the strong wave-backwash interaction for event A. The cross-shore location of wave capture has a large effect on uprush transport, as it determines whether a swash front propagates over a dry bed (leading to high bed shear stress) or whether it propagates over a preceding, smaller bore (which reduces the bed shear stress) (Barnes et al., 2009; Baldock et al., 2014). Wave capture also leads to high turbulence production (Chen et al., 2016) and high turbulence levels are expected landward of the capture point. The higher mobilization of sediment as sheet load and suspended load by the uprush of event B, which had the wave capture point located further seaward than event A, likely connects to these hydrodynamic processes. The strong wave-backwash interaction for event $\mathrm{A}$ is also effective in terms of mobilizing sediment, increasing SFL thickness as well as suspended sand concentrations. This is consistent with previous suspension measurements (Hughes and Moseley, 2007; Cáceres and Alsina, 2012; Alsina et al., 2018) and can be explained by the high turbulence levels generated by velocity shearing as the backwash and incident bore collide and a stationary bore is formed (Chen et al., 2016).

The wave-swash interactions also affect the net transport and, consequently, bed level changes in the swash. It is likely that the location of the 
cross-shore maximum in uprush transport relates to the location of wave capture during the uprush: landward from this location, the merged, highly turbulent bore propagates over a dry bed and is expected to induce high bed shear stresses and sediment mobilization. As the bore propagates landward throughout the swash, bed shear stresses and turbulence levels are expected to reduce as the turbulent energy dissipates and the bore is retarded by gravity. One may therefore expect maximum landward transport shortly landward from the wave capture location. This explanation is supported by the differences in uprush transport for events A and B. Strong wave-backwash interactions interrupt the backwash velocity and reduce the seaward transport. The weak wave-backwash interaction appears to have little effect on sediment transport processes and rates. Note that the present study only covers a small number of wave-swash interactions and further study is required to verify the generality of these results.

\subsection{Net morphodynamic change}

The results in Section 4 reveal significant mobilization and transport of sediment as sheet flow and suspended load in the lower to mid swash zone. This contrasts with the inner surf-lower swash boundary, where measured sediment concentrations and sheet flow layer thicknesses are low. This possibly reflects much lower bed shear stresses in the inner surf zone compared to the lower swash (see e.g., Barnes et al., 2009). Moreover, the measurements indicate a considerable increase in net transport rates by single events in the lower swash zone compared to the surf-swash boundary. These results imply that most of the sand transported in the swash zone was mobilized within the swash zone, and that the contribution of pre-suspended sediment, 
mobilized in the inner surf zone and then imported into the swash zone, was considerably smaller. This contrasts with field observations (Jackson et al., 2004; Hughes and Moseley, 2007) and numerical studies (Pritchard and Hogg, 2005; Alsina et al., 2009) that found significant contributions of pre-suspended sediment to the total transport in the swash. Differences with the field observations may relate to variations in the determining of the moving surf-swash boundary. The differences with numerical studies may partly relate to the significant effects of swash-specific processes, e.g., the bore run-up over a dry bed and the wave-backwash interactions, that were not (fully) incorporated in the numerical model formulations for sediment transport. Note that although the sand exchange between the surf and swash is relatively small (compared to transport rates within the swash zone) at intra-swash time scale, the results show that its significance to swash zone morphologic change increases progressively with time scale (i.e., from intra-swash, to event-averaged, to averaged over multiple events). The relative significance of the sediment advection across the surf-swash boundary compared to sediment that is mobilized within the swash zone is summarized for different time scales in Table 2.

The measurements further show a large variability between swash events, with opposite net transport rates and bed level changes for events A and B. The net transport and morphodynamic change over the two events combined is the small difference between transport and changes in opposite directions. At intra-swash time scale (Section 4.3), transport rates and bed level changes are even greater. The decrease in the transport rate and morphodynamic change of interest with increasing time scales is summarized 
for the present study in Table 2. These results are in line with field observations that showed that various single erosive and accretive events can nearly balance in terms of net transport, leading to small morphodynamic rates of change at longer time scales (Masselink et al., 2009; Blenkinsopp et al., 2011). Hence, the present experiment reaffirms the need for methods to upscale the short-term processes to longer-term beach evolution, which is considered one of the main challenges for research on swash morphodynamics (Chardón-Maldonado et al., 2016).

\section{Conclusions}

Measurements are presented of a large-scale wave flume experiment that involved two alternating swash events $\mathrm{A}$ and $\mathrm{B}$, formed by two bichromatic wave groups with a phase modulation.

Event A is characterized by a strong uprush with high velocity and runup length that contributes to building of the berm in the upper swash. Its backwash reaches high seaward-directed velocity and erodes the mid swash, but the interruption of the backwash flow by a third incident bore induces deposition of sediment in the lower swash.

Event B is characterized by two uprush and backwash events, with generally lower velocities and weaker wave-swash interactions than for event A. The primary uprush of event $\mathrm{B}$ is formed by two incident bores that merge close to the surf-swash boundary. The uprush propagates over an exposed bed in the lower swash, leading to net erosion at these locations, and advects the eroded sediment landward to the mid swash, leading to local net accretion. 
Together, the two alternating swash events produce a dynamic equilibrium of the bed, where bed level changes induced by single events are significant (up to $8 \mathrm{~mm}$ ) but the net bed change integrated over the two events is relatively small (up to $1 \mathrm{~mm}$ ). These net changes become nevertheless significant when integrated over time scales of minutes to hours, and it explains the gradual erosion of the swash zone as observed with bed profiler measurements in the present experiment.

The observations of sediment transport processes further lead to the following specific conclusions:

- The mobilization of sediment as suspended and sheet load increases significantly landward from the wave capture point (where a large incident bore overtakes a preceding, smaller, incident bore). Consequently, the location of wave capture has a large effect on sand resuspension and transport during the uprush. No clear relation is found between crossshore pressure gradients and sheet flow layer growth.

- Sheet flow and suspended load transport rates in the lower swash are generally of the same order of magnitude, but the sheet flow transport exceeds the suspended transport by a factor four during the early uprush stage. Sheet flow is further expected to dominate during the final backwash stage.

- Instantaneous bed level changes $(\mathcal{O}(\mathrm{cm} / \mathrm{s}))$ are highest in the lower swash zone and occur especially during the early uprush and during instants of strong wave-swash interactions during the backwash. This relates to the strongly non-uniform flow at these moments. For the 
same reason, also the net bed level changes (integrated over single swash events) are maximum in the lower swash zone.

- Sand transport rates and bed level changes at intra-swash time scales can be orders of magnitude greater than the net transport rates and bed level change integrated over both events.

- Also the relative importance of the sand exchange between surf and swash zone varies with time scale. At intra-swash time scales and integrated over single swash events, the advection across the surf-swash boundary is of minor significance and bed level changes in the swash are primarily explained by sand redistribution within the swash. However, at time scales over multiple events or over 60-min experimental runs, the net sand exchange between the surf and swash zone becomes increasingly important.

\section{Acknowledgments}

The experiments described in this publication were supported by the European Communitys Horizon 2020 Programme through the grant to the budget of the Integrated Infrastructure Initiative $\mathrm{HYDRALAB}+$, Contract no. 654110, and was conducted as part of the transnational access project RESIST. JvdZ and JJvdW gratefully acknowledge funding by NWO-TTW (contract no. 16130) and SE gratefully acknowledges funding from the Department of Civil and Environmental Engineering, Imperial College London. We thank fellow RESIST researchers and the CIEMLAB staff (Oscar Galego, Andrea Marzeddu, and Joaquim Sospedra) for their contributions to the ex- 
periments. Finally, we are grateful to the two reviewers for their constructive feedback on the initial submitted manuscript.

\section{References}

Aagaard, T., Hughes, M. G., 2006. Sediment suspension and turbulence in the swash zone of dissipative beaches. Marine Geology 228 (1-4), 117-135.

Almeida, L. P., Masselink, G., Russell, P. E., Davidson, M. A., 2015. Observations of gravel beach dynamics during high energy wave conditions using a laser scanner. Geomorphology 228, 15-27.

Alsina, J. M., Cáceres, I., 2011. Sediment suspension events in the inner surf and swash zone. measurements in large-scale and high-energy wave conditions. Coastal Engineering 58 (8), 657-670.

Alsina, J. M., Cáceres, I., Brocchini, M., Baldock, T. E., 2012. An experimental study on sediment transport and bed evolution under different swash zone morphological conditions. Coastal Engineering 68, 31-43.

Alsina, J. M., Falchetti, S., Baldock, T. E., 2009. Measurements and modelling of the advection of suspended sediment in the swash zone by solitary waves. Coastal Engineering 56 (5-6), 621-631.

Alsina, J. M., Padilla, E. M., Cáceres, I., 2016. Sediment transport and beach profile evolution induced by bi-chromatic wave groups with different group periods. Coastal Engineering 114, 325-340. 
Alsina, J. M., van der Zanden, J., Cáceres, I., Ribberink, J. S., 2018. The influence of wave groups and wave-swash interactions on sediment transport and bed evolution in the swash zone. Coastal Engineering 140, 23-42.

Astruc, D., Cazin, S., Cid, E., Eiff, O., Lacaze, L., Robin, P., Toublanc, F., Cáceres, I., 2012. A stereoscopic method for rapid monitoring of the spatiotemporal evolution of the sand-bed elevation in the swash zone. Coastal Engineering 60, 11-20.

Bakhtyar, R., Barry, D. A., Yeganeh-Bakhtiary, A., Li, L., Parlange, J. Y., Sander, G. C., 2010. Numerical simulation of two-phase flow for sediment transport in the inner-surf and swash zones. Advances in Water Resources 33 (3), 277-290.

Baldock, T. E., 2006. Long wave generation by the shoaling and breaking of transient wave groups on a beach. Proceedings of the Royal Society a-Mathematical Physical and Engineering Sciences 462 (2070), 1853-1876.

Baldock, T. E., 2012. Dissipation of incident forced long waves in the surf zoneimplications for the concept of bound wave release at short wave breaking. Coastal Engineering 60, 276-285.

Baldock, T. E., Alsina, J. M., Cáceres, I., Vicinanza, D., Contestabile, P., Power, H., Sanchez-Arcilla, A., 2011. Large-scale experiments on beach profile evolution and surf and swash zone sediment transport induced by long waves, wave groups and random waves. Coastal Engineering 58 (2), $214-227$. 
Baldock, T. E., Birrien, F., Atkinson, A., Shimamoto, T., Wu, S., Callaghan, D. P., Nielsen, P., 2017. Morphological hysteresis in the evolution of beach profiles under sequences of wave climates - part 1; observations. Coastal Engineering 128, 92-105.

Baldock, T. E., Grayson, R., Torr, B., Power, H. E., 2014. Flow convergence at the tip and edges of a viscous swash front experimental and analytical modeling. Coastal Engineering 88, 123-130.

Baldock, T. E., Hughes, M. G., 2006. Field observations of instantaneous water slopes and horizontal pressure gradients in the swash-zone. Continental Shelf Research 26 (5), 574-588.

Baldock, T. E., Huntley, D. A., Bird, P. A. D., O'Hare, T., Bullock, G. N., 2000. Breakpoint generated surf beat induced by bichromatic wave groups. Coastal Engineering 39 (2-4), 213-242.

Barnes, M. P., Baldock, T. E., 2010. A lagrangian model for boundary layer growth and bed shear stress in the swash zone. Coastal Engineering 57 (4), $385-396$.

Barnes, M. P., O’Donoghue, T., Alsina, J. M., Baldock, T. E., 2009. Direct bed shear stress measurements in bore-driven swash. Coastal Engineering $56(8), 853-867$.

Battjes, J. A., Bakkenes, H. J., Janssen, T. T., van Dongeren, A. R., 2004. Shoaling of subharmonic gravity waves. Journal of Geophysical Research 109 (C2). 
Blenkinsopp, C., Mole, M. E., Turner, I. L., Peirson, W. L., 2010. Measurements of the time-varying profile across the swash zone using an industrial lidar. Coastal Engineering.

Blenkinsopp, C. E., Turner, I. L., Masselink, G., Russell, P. E., 2011. Swash zone sediment fluxes: Field observations. Coastal Engineering 58 (1), 28 44.

Bonneton, P., Lannes, D., Martins, K., Michallet, H., 2018. A nonlinear weakly dispersive method for recovering the elevation of irrotational surface waves from pressure measurements. Coastal Engineering 138, 1-8.

Briganti, R., Dodd, N., Pokrajac, D., O’Donoghue, T., 2011. Non linear shallow water modelling of bore-driven swash: Description of the bottom boundary layer. Coastal Engineering 58 (6), 463-477.

Briganti, R., Torres-Freyermuth, A., Baldock, T. E., Brocchini, M., Dodd, N., Hsu, T.-J., Jiang, Z., Kim, Y., Pintado-Patiño, J. C., Postacchini, M., 2016. Advances in numerical modelling of swash zone dynamics. Coastal Engineering 115, 26-41.

Brocchini, M., Baldock, T. E., 2008. Recent advances in modeling swash zone dynamics: Influence of surf-swash interaction on nearshore hydrodynamics and morphodynamics. Reviews of Geophysics 46 (3).

Brocchini, M., Peregrine, D. H., 1996. Integral flow properties of the swash zone and averaging. Journal of Fluid Mechanics 317, 241-273.

Butt, T., Russell, P., 1999. Suspended sediment transport mechanisms in high-energy swash. Marine Geology 161 (2-4), 361-375. 
Cáceres, I., Alsina, J. M., 2012. A detailed, event-by-event analysis of suspended sediment concentration in the swash zone. Continental Shelf Research 41, 61-76.

Cáceres, I., Alsina, J. M., 2016. Suspended sediment transport and beach dynamics induced by monochromatic conditions, long waves and wave groups. Coastal Engineering 108, 36-55.

Caliskan, U., Fuhrman, D. R., 2017. Rans-based simulation of wave-induced sheet-flow transport of graded sediments. Coastal Engineering 121, 90-102.

Chardón-Maldonado, P., Pintado-Patiño, J. C., Puleo, J. A., 2016. Advances in swash-zone research: Small-scale hydrodynamic and sediment transport processes. Coastal Engineering 115, 8-25.

Chen, B.-T., Kikkert, G. A., Pokrajac, D., Dai, H.-J., 2016. Experimental study of bore-driven swash-swash interactions on an impermeable rough slope. Coastal Engineering 108, 10-24.

Dohmen-Janssen, C. M., Hanes, D., 2002. Sheet flow dynamics under monochromatic nonbreaking waves. Journal of Geophysical Research 107 (C10).

Dohmen-Janssen, C. M., Hanes, D. M., 2005. Sheet flow and suspended sediment due to wave groups in a large wave flume. Continental Shelf Research 25 (3), 333-347.

Dohmen-Janssen, C. M., Hassan, W. N., Ribberink, J. S., 2001. Mobile-bed effects in oscillatory sheet flow. Journal of Geophysical Research-Oceans 106 (C11), 27103-27115. 
Downing, J. P., Beach, R. A., 1989. Laboratory apparatus for calibrating optical suspended solids sensors. Marine Geology 86 (2-3), 243-249.

Eichentopf, S., van der Zanden, J., Cáceres, I., Baldock, T., Alsina, J. M., 2019. Influence of storm sequencing on breaker bar and shoreline evolution in large-scale experiments. Coastal Engineering, in preparation.

Fromant, G., Hurther, D., van der Zanden, J., van der A, D. A., Cáceres, I., ODonoghue, T., Ribberink, J. S., 2018. Wave boundary layer hydrodynamics and sheet flow properties under large-scale plunging-type breaking waves. Journal of Geophysical Research: Oceans.

Hassan, W. N., Ribberink, J. S., 2005. Transport processes of uniform and mixed sands in oscillatory sheet flow. Coastal Engineering 52 (9), 745-770.

Hibberd, S., Peregrine, D. H., 1979. Surf and run-up on a beach - uniform bore. Journal of Fluid Mechanics 95 (Nov), 323-345.

Higuera, P., Liu, P. L. F., Lin, C., Wong, W. Y., Kao, M. J., 2018. Laboratory-scale swash flows generated by a non-breaking solitary wave on a steep slope. Journal of Fluid Mechanics 847, 186-227.

Holmedal, L. E., Myrhaug, D., Eidsvik, K. J., 2004. Sediment suspension under sheet flow conditions beneath random waves plus current. Continental Shelf Research 24 (17), 2065-2091.

Horn, D. P., Mason, T., 1994. Swash zone sediment transport modes. Marine Geology 120 (3-4), 309-325. 
Hughes, M., 1995. Friction factor for wave uprush. Journal of Coastal Research 11 (4), 1069-1096.

Hughes, M. G., Moseley, A. S., 2007. Hydrokinematic regions within the swash zone. Continental Shelf Research 27 (15), 2000-2013.

Incelli, G., Dodd, N., Blenkinsopp, C. E., Zhu, F., Briganti, R., 2016. Morphodynamical modelling of field-scale swash events. Coastal Engineering $115,42-57$.

Jackson, N. L., Masselink, G., Nordstrom, K. F., 2004. The role of bore collapse and local shear stresses on the spatial distribution of sediment load in the uprush of an intermediate-state beach. Marine Geology 203 (12), 109-118.

Janssen, T. T., Battjes, J. A., van Dongeren, A. R., 2003. Long waves induced by short-wave groups over a sloping bottom. Journal of Geophysical Research-Oceans 108 (C8), 1-14.

Jonsson, I. G., 1980. A new approach to oscillatory rough turbulent boundary layers. Ocean Engineering 7 (1), 109-152.

Kikkert, G. A., O’Donoghue, T., Pokrajac, D., Dodd, N., 2012. Experimental study of bore-driven swash hydrodynamics on impermeable rough slopes. Coastal Engineering 60, 149-166.

Kikkert, G. A., Pokrajac, D., O’Donoghue, T., Steenhauer, K., 2013. Experimental study of bore-driven swash hydrodynamics on permeable rough slopes. Coastal Engineering 79, 42-56. 
Kim, Y., Zhou, Z., Hsu, T.-J., Puleo, J. A., 2017. Large eddy simulation of dam-break-driven swash on a rough-planar beach. Journal of Geophysical Research: Oceans 122 (2), 1274-1296.

Kobayashi, N., Johnson, B. D., 2001. Sand suspension, storage, advection, and settling in surf and swash zones. Journal of Geophysical Research 106 (C5), 9363-9376.

Kranenburg, W. M., Ribberink, J. S., Schretlen, J. J. L. M., Uittenbogaard, R. E., 2013. Sand transport beneath waves: The role of progressive wave streaming and other free surface effects. Journal of Geophysical Research: Earth Surface 118 (1), 122-139.

Lanckriet, T., Puleo, J. A., 2015. A semianalytical model for sheet flow layer thickness with application to the swash zone. Journal of Geophysical Research-Oceans 120 (2), 1333-1352.

Lanckriet, T., Puleo, J. A., Masselink, G., Turner, I. L., Conley, D., Blenkinsopp, C., Russell, P., 2014. Comprehensive field study of swash-zone processes. ii: Sheet flow sediment concentrations during quasi-steady backwash. Journal of Waterway, Port, Coastal, and Ocean Engineering 140 (1), 29-42.

Lara, J. L., Ruju, A., Losada, I. J., 2011. Reynolds averaged navier-stokes modelling of long waves induced by a transient wave group on a beach. Proceedings of the Royal Society A: Mathematical, Physical and Engineering Sciences 467 (2129), 1215-1242. 
Li, Z., Davies, A. G., 2001. Turbulence closure modelling of sediment transport beneath large waves. Continental Shelf Research 21 (3), 243-262.

Longuet-Higgins, M. S., Stewart, R. W., 1962. Radiation stress and mass transport in gravity waves, with application to surf beats. Journal of Fluid Mechanics 13 (04), 481.

Masselink, G., Evans, D., Hughes, M. G., Russell, P., 2005. Suspended sediment transport in the swash zone of a dissipative beach. Marine Geology 216 (3), 169-189.

Masselink, G., Hughes, M., 1998. Field investigation of sediment transport in the swash zone. Continental Shelf Research 18 (10), 1179-1199.

Masselink, G., Puleo, J. A., 2006. Swash-zone morphodynamics. Continental Shelf Research 26 (5), 661-680.

Masselink, G., Russell, P., Turner, I., Blenkinsopp, C., 2009. Net sediment transport and morphological change in the swash zone of a high-energy sandy beach from swash event to tidal cycle time scales. Marine Geology $267(1-2), 18-35$.

McLean, S. R., Ribberink, J. S., Dohmen-Janssen, C. M., Hassan, W. N., 2001. Sand transport in oscillatory sheet flow with mean current. Journal of Waterway, Port, Coastal, and Ocean Engineering 127 (3), 141-151.

Mieras, R. S., Puleo, J. A., Anderson, D., Cox, D. T., Hsu, T.-J., 2017. Largescale experimental observations of sheet flow on a sandbar under skewedasymmetric waves. Journal of Geophysical Research: Oceans 122 (6), 50225045. 
O’Donoghue, T., Kikkert, G. A., Pokrajac, D., Dodd, N., Briganti, R., 2016. Intra-swash hydrodynamics and sediment flux for dambreak swash on coarse-grained beaches. Coastal Engineering 112, 113-130.

O’Donoghue, T., Pokrajac, D., Hondebrink, L. J., 2010. Laboratory and numerical study of dambreak-generated swash on impermeable slopes. Coastal Engineering 57 (5), 513-530.

O'Donoghue, T., Wright, S., 2004a. Concentrations in oscillatory sheet flow for well sorted and graded sands. Coastal Engineering 50 (3), 117-138.

O'Donoghue, T., Wright, S., 2004b. Flow tunnel measurements of velocities and sand flux in oscillatory sheet flow for well-sorted and graded sands. Coastal Engineering 51 (11-12), 1163-1184.

Osborne, P. D., Rooker, G. A., 1999. Sand re-suspension events in a high energy infragravity swash zone. Journal of Coastal Research 15 (1), 74-86.

Othman, I. K., Baldock, T. E., Callaghan, D. P., 2014. Measurement and modelling of the influence of grain size and pressure gradient on swash uprush sediment transport. Coastal Engineering 83, 1-14.

Padilla, E. M., Alsina, J. M., 2017. Transfer and dissipation of energy during wave group propagation on a gentle beach slope. Journal of Geophysical Research: Oceans 122 (8), 6773-6794.

Padilla, E. M., Alsina, J. M., 2018. Long wave generation induced by differences in the wavegroup structure. Journal of Geophysical Research: Oceans 123 (12), 8921-8940. 
Peregrine, D. H., 1974. Water-wave interactions in the surf zone. In: Proceedings of 14th Conference on Coastal Engineering, Copenhagen Denmark. pp. $500-517$.

Pintado-Patiño, J. C., Torres-Freyermuth, A., Puleo, J. A., Pokrajac, D., 2015. On the role of infiltration and exfiltration in swash zone boundary layer dynamics. Journal of Geophysical Research: Oceans 120 (9), 63296350.

Postacchini, M., Brocchini, M., Mancinelli, A., Landon, M., 2012. A multipurpose, intra-wave, shallow water hydro-morphodynamic solver. Advances in Water Resources 38, 13-26.

Postacchini, M., Othman, I. K., Brocchini, M., Baldock, T. E., 2014. Sediment transport and morphodynamics generated by a dam-break swash uprush: Coupled vs uncoupled modeling. Coastal Engineering 89, 99-105.

Pritchard, D., Hogg, A. J., 2005. On the transport of suspended sediment by a swash event on a plane beach. Coastal Engineering 52 (1), 1-23.

Pujara, N., Liu, P. L. F., Yeh, H., 2015a. The swash of solitary waves on a plane beach: flow evolution, bed shear stress and run-up. Journal of Fluid Mechanics 779, 556-597.

Pujara, N., Liu, P. L. F., Yeh, H. H., 2015b. An experimental study of the interaction of two successive solitary waves in the swash: A strongly interacting case and a weakly interacting case. Coastal Engineering 105, $66-74$. 
Puleo, J. A., Beach, R. A., Holman, R. A., Allen, J. S., 2000. Swash zone sediment suspension and transport and the importance of bore-generated turbulence. Journal of Geophysical Research 105 (C7), 17021.

Puleo, J. A., Krafft, D., Pintado-Patiño, J. C., Bruder, B., 2017. Videoderived near bed and sheet flow sediment particle velocities in dam-breakdriven swash. Coastal Engineering 126, 27-36.

Puleo, J. A., Lanckriet, T., Blenkinsopp, C., 2014. Bed level fluctuations in the inner surf and swash zone of a dissipative beach. Marine Geology 349, 99-112.

Puleo, J. A., Lanckriet, T., Conley, D., Foster, D., 2016. Sediment transport partitioning in the swash zone of a large-scale laboratory beach. Coastal Engineering 113, 73-87.

Ribberink, J. S., Al-Salem, A. A., 1995. Sheet flow and suspension of sand in oscillatory boundary-layers. Coastal Engineering 25 (3-4), 205-225.

Ruffini, G., Briganti, R., Alsina, J. M., Brocchini, M., Dodd, N., McCall, R., 2019. Numerical modelling of flow and bed evolution of bichromatic wave groups on an intermediate beach using non-hydrostatic xbeach. Journal of Waterway Port Coastal and Ocean Engineering in press.

Ruju, A., Conley, D., Masselink, G., Puleo, J., 2016. Sediment transport dynamics in the swash zone under large-scale laboratory conditions. Continental Shelf Research 120, 1-13.

Sánchez-Arcilla, A., Cáceres, I., 2017. An analysis of nearshore profile and 
bar development under large scale erosive and accretive waves. Journal of Hydraulic Research 56 (2), 231-244.

Schretlen, J., 2012. Sand transport under full-scale progressive surface waves. Phd thesis, University of Twente, The Netherlands.

Shen, M. C., Meyer, R. E., 1963. Climb of a bore on a beach part 3. run-up. Journal of Fluid Mechanics 16 (01), 113.

Sou, I. M., Yeh, H., 2011. Laboratory study of the cross-shore flow structure in the surf and swash zones. Journal of Geophysical Research 116 (C3).

Sumer, B. M., Kozakiewicz, A., Fredsoe, J., Deigaard, R., 1996. Velocity and concentration profiles in sheet-flow layer of movable bed. Journal of Hydraulic Engineering 122 (10), 549-558.

Symonds, G., Huntley, D. A., Bowen, A. J., 1982. Two-dimensional surf beat: Long wave generation by a time-varying breakpoint. Journal of Geophysical Research 87 (C1), 492.

Tissier, M., Bonneton, P., Michallet, H., Ruessink, B. G., 2015. Infragravitywave modulation of short-wave celerity in the surf zone. Journal of Geophysical Research: Oceans 120 (10), 6799-6814.

Torres-Freyermuth, A., Puleo, J. A., Pokrajac, D., 2013. Modeling swashzone hydrodynamics and shear stresses on planar slopes using reynoldsaveraged navier-stokes equations. Journal of Geophysical Research: Oceans 118 (2), 1019-1033. 
van der Zanden, J., Alsina, J. M., Cáceres, I., Buijsrogge, R. H., Ribberink, J. S., 2015. Bed level motions and sheet flow processes in the swash zone: Observations with a new conductivity-based concentration measuring technique $(\mathrm{ccm}+)$. Coastal Engineering 105, 47-65.

van der Zanden, J., van der A, D. A., Cáceres, I., Larsen, B. E., Fromant, G., Petrotta, C., Scandura, P., Li, M., 2019. Spatial and temporal distributions of turbulence under bichromatic breaking waves. Coastal Engineering 146, 65-80.

van der Zanden, J., van der A, D. A., Hurther, D., Cáceres, I., O’Donoghue, T., Hulscher, S. J. M. H., Ribberink, J. S., 2017. Bedload and suspended load contributions to breaker bar morphodynamics. Coastal Engineering 129, 74-92.

van Dongeren, A., Battjes, J., Janssen, T., van Noorloos, J., Steenhauer, K., Steenbergen, G., Reniers, A., 2007. Shoaling and shoreline dissipation of low-frequency waves. Journal of Geophysical Research 112 (C2).

van Rijn, L. C., 2007. Unified view of sediment transport by currents and waves. i: Initiation of motion, bed roughness, and bed-load transport. Journal of Hydraulic Engineering-Asce 133 (6), 649-667.

van Rijn, L. C., Ribberink, J. S., van der Werf, J. J., Walstra, D. J. R., 2013. Coastal sediment dynamics: recent advances and future research needs. Journal of Hydraulic Research 51 (5), 475-493.

Wang, Y.-H., Yu, G.-H., 2007. Velocity and concentration profiles of particle movement in sheet flows. Advances in Water Resources 30 (5), 1355-1359. 
1599 Weir, F. M., Hughes, M. G., Baldock, T. E., 2006. Beach face and berm

1600

1601 morphodynamics fronting a coastal lagoon. Geomorphology 82 (3-4), 331346.

Wilson, K. C., 1966. Bed-load transport at high shear stress. Journal of the Hydraulics Division 92 (6), 49-59.

Wu, L., Feng, D., Shimozono, T., Okayasu, A., 2016. Laboratory measurements of sediment flux and bed level evolution in the swash zone. Coastal Engineering Journal 58 (02), 1650004.

Zhu, F., Dodd, N., 2013. Net beach change in the swash zone: A numerical investigation. Advances in Water Resources 53, 12-22.

Zhu, F. F., Dodd, N., 2015. The morphodynamics of a swash event on an erodible beach. Journal of Fluid Mechanics 762, 110-140. 
Table 1: Positions of instruments in the swash zone. Vertical positions with respect to the bed level at the start of each experimental run are only given when relevant.

\begin{tabular}{l|l|l}
\hline Instrument & $x(\mathrm{~m})$ & $z-z_{\text {bed }}(\mathrm{m})$ \\
\hline \hline $\mathrm{CCM}^{+}$ & $1.28(\operatorname{tank} 1),-0.52(\operatorname{tank} 2)$ & \\
\hline $\mathrm{ADVs}$ & $-1.54,-0.52,0.27,1.28,2.26$ & 0.03 \\
\hline OBSs & $-1.68,-0.45,0.38,1.28,2.36$ & 0.03 \\
\hline PTs & $1.23,1.28,1.33$ & -0.01 \\
\hline AWGs & $-1.57,-0.52,0.47,1.25,2.31,3.5,4.55,5.56,6.51$ & \\
\hline
\end{tabular}

Table 2: Magnitudes of sand transport rates and bed level changes in the lower swash zone, and relative significance of sediment exchange across the surf-swash boundary compared to sediment mobilized within the swash zone, at different time scales.

\begin{tabular}{l|l|l|l|l}
\hline Time scale & $\begin{array}{l}q_{\text {tot }} \\
(\mathrm{kg} / \mathrm{ms})\end{array}$ & $\begin{array}{l}\Delta z_{\text {bed }} / \Delta t \\
(\mathrm{~mm} / \mathrm{s})\end{array}$ & $\begin{array}{l}\Delta z_{\text {bed }} \\
(\mathrm{mm})\end{array}$ & $\begin{array}{l}\text { Significance } \\
\text { surf-swash } \\
\text { exchange }\end{array}$ \\
\hline \hline Intra-swash & 1 to 10 & 1 to 15 & 2 to 20 & Low \\
\hline $\begin{array}{l}\text { Integrated over } \\
\text { one swash event }\end{array}$ & 0.1 to 0.5 & 0.1 to 0.5 & 2 to 8 & Moderately low \\
\hline $\begin{array}{l}\text { Integrated over } \\
\text { both events }\end{array}$ & $0.01 \quad$ to & 0.005 to & 0.05 to 1 & High \\
\hline $\begin{array}{l}\text { Integrated over } \\
60-m i n \text { run }\end{array}$ & $\begin{array}{l}0.01 \\
0.05\end{array}$ & $\begin{array}{l}0.005 \text { to } \\
0.02\end{array}$ & & High \\
\hline
\end{tabular}



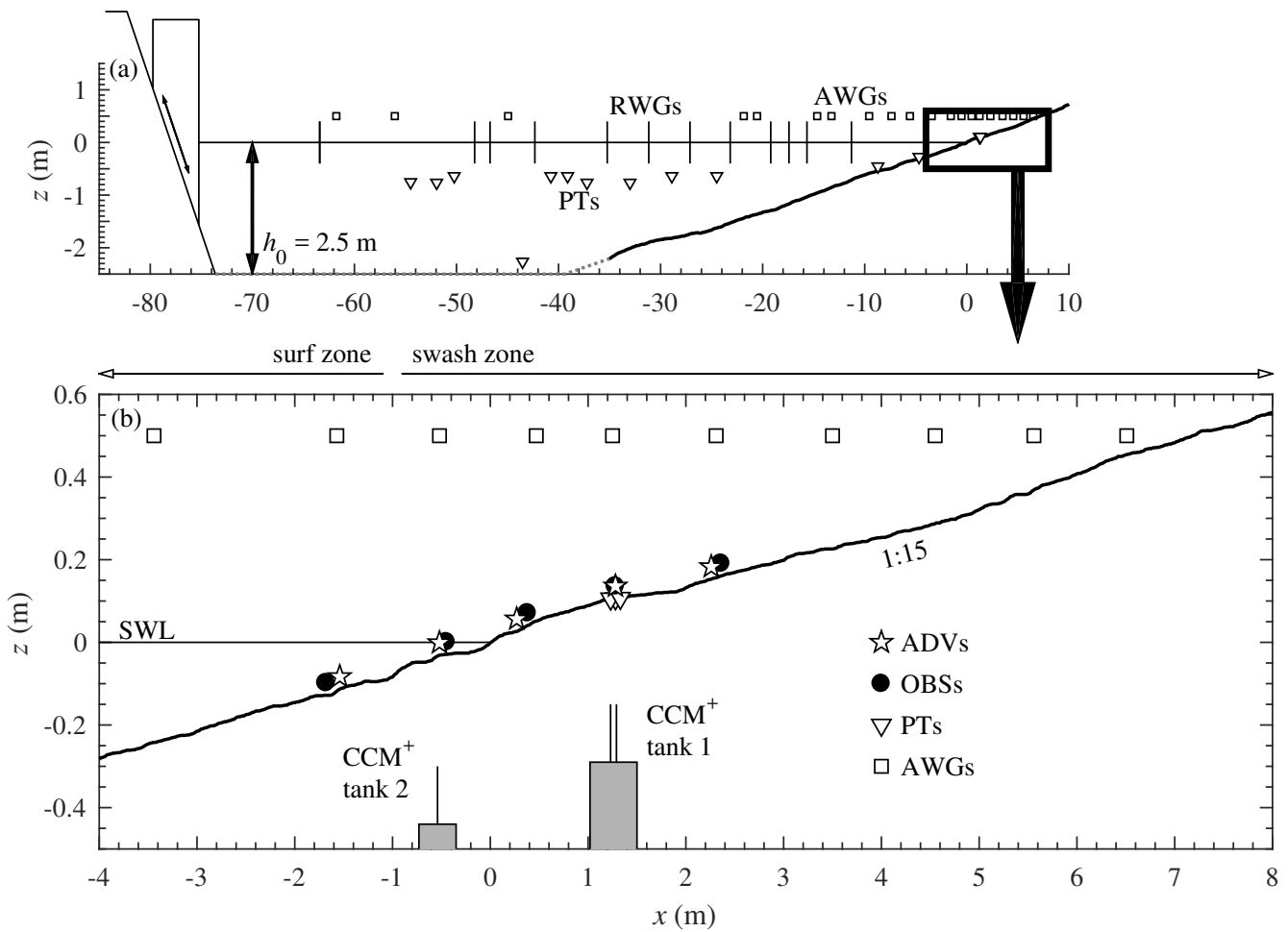

Figure 1: Experimental set-up: initial 1:15 sloping bed and position of instruments. 

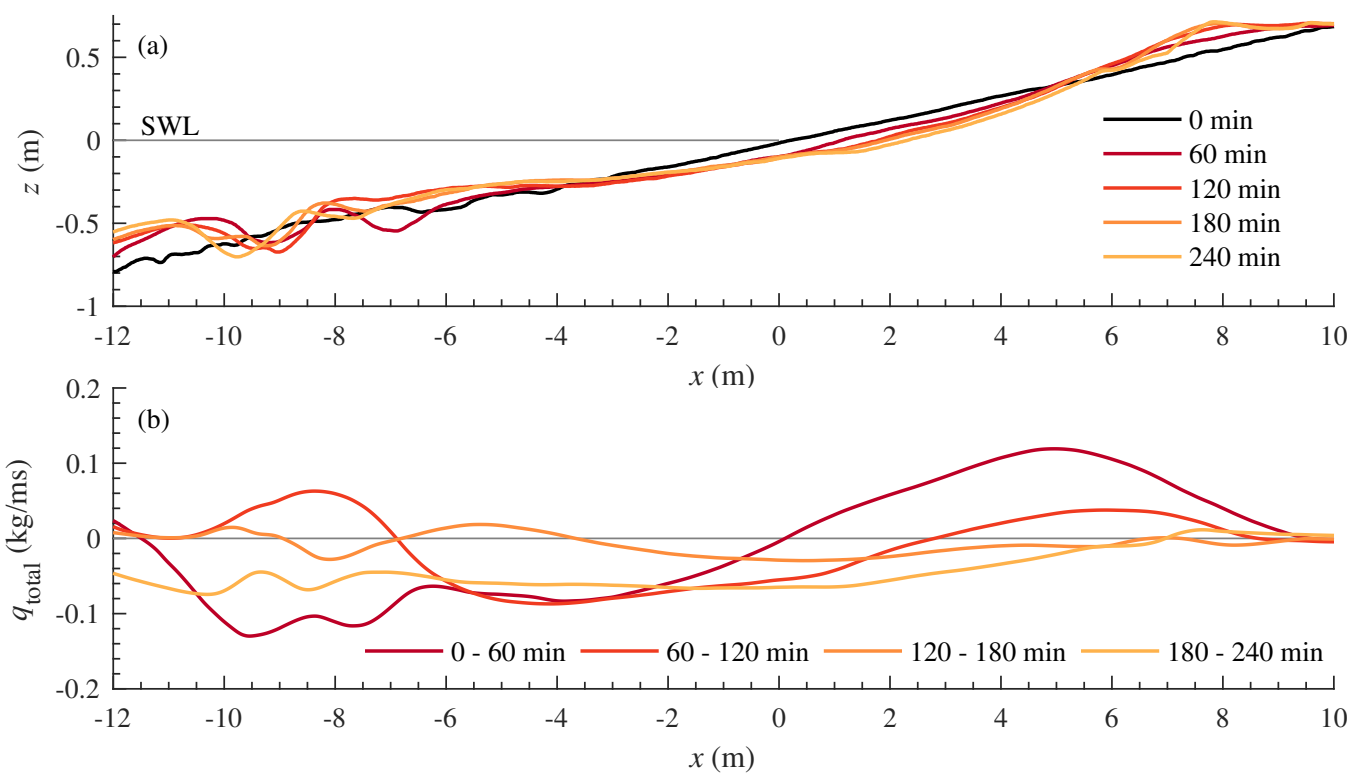

Figure 2: (a) Bed profile evolution; (b) Net sand transport rates obtained through Equation 1. 


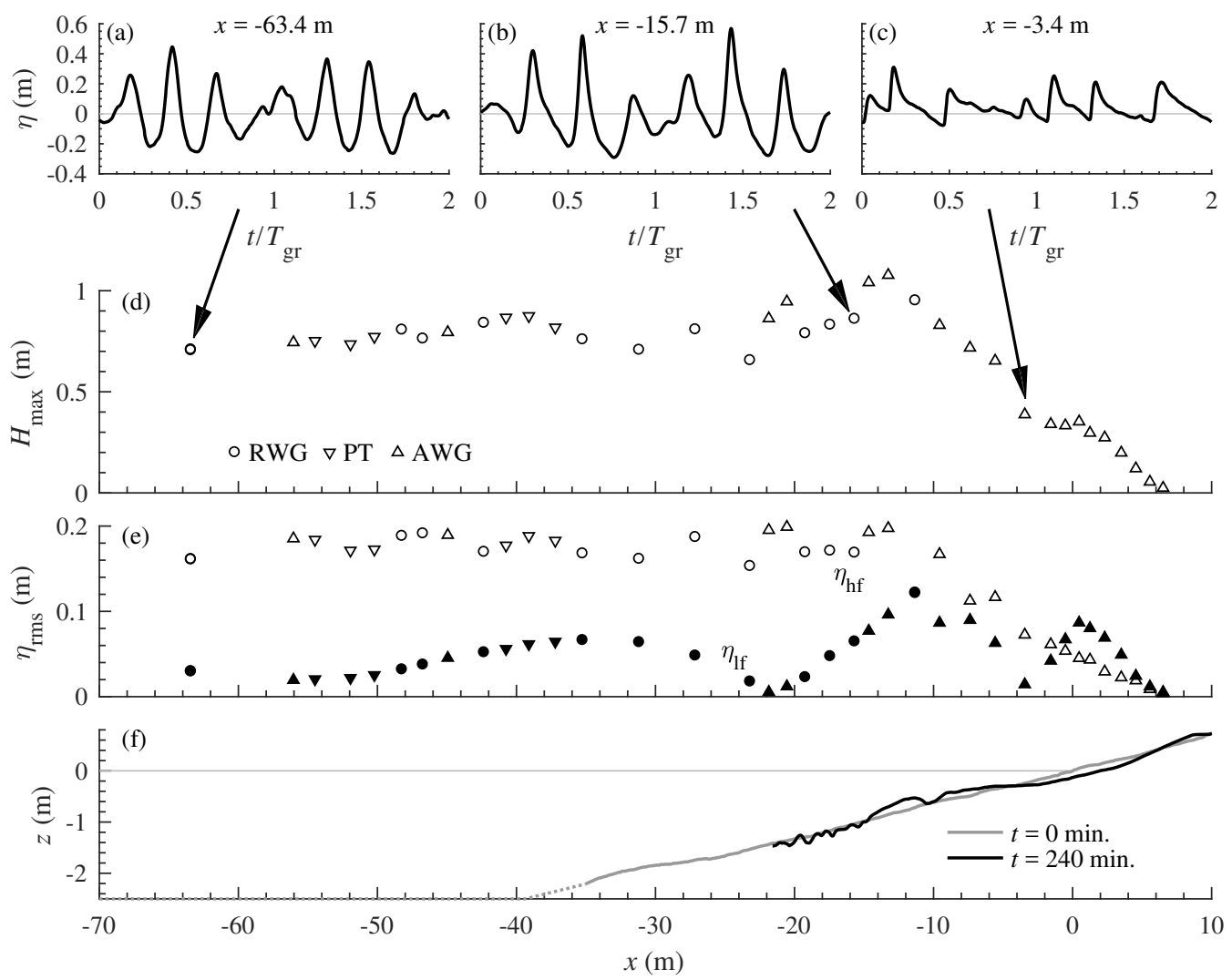

Figure 3: $(\mathrm{a}, \mathrm{b}, \mathrm{c})$ Time series of phase-averaged water surface elevation at three locations; (d) $H_{\max }=\eta_{\max }-\eta_{\min }$, measured with RWGs (circles), pressure transducers (downward triangles) and acoustic wave gauges (upward triangles); e) root-mean-square high-pass ("hf", open markers) and low-pass ("lf", solid markers) filtered water surface elevation, corresponding to short waves and wave groups, respectively; f) initial (grey) and final (black) bed profile. 

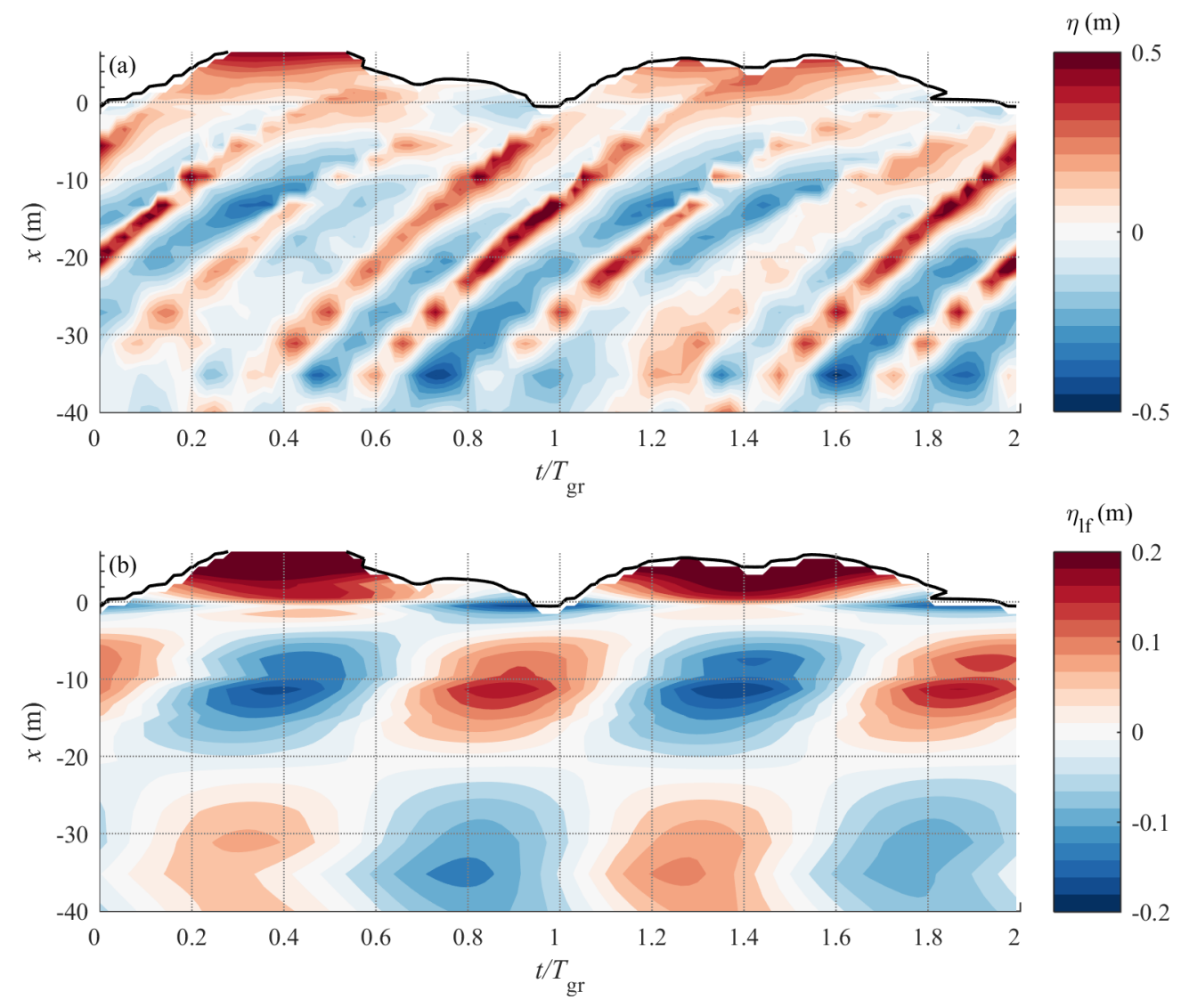

Figure 4: Colour contour of the phase-averaged water surface elevation along the entire flume: (a) $\eta$, (b) $\eta_{\mathrm{lf}}$. The solid black line is the $h=0.01 \mathrm{~m}$ iso-line, highlighted here as a proxy for the shoreline. 

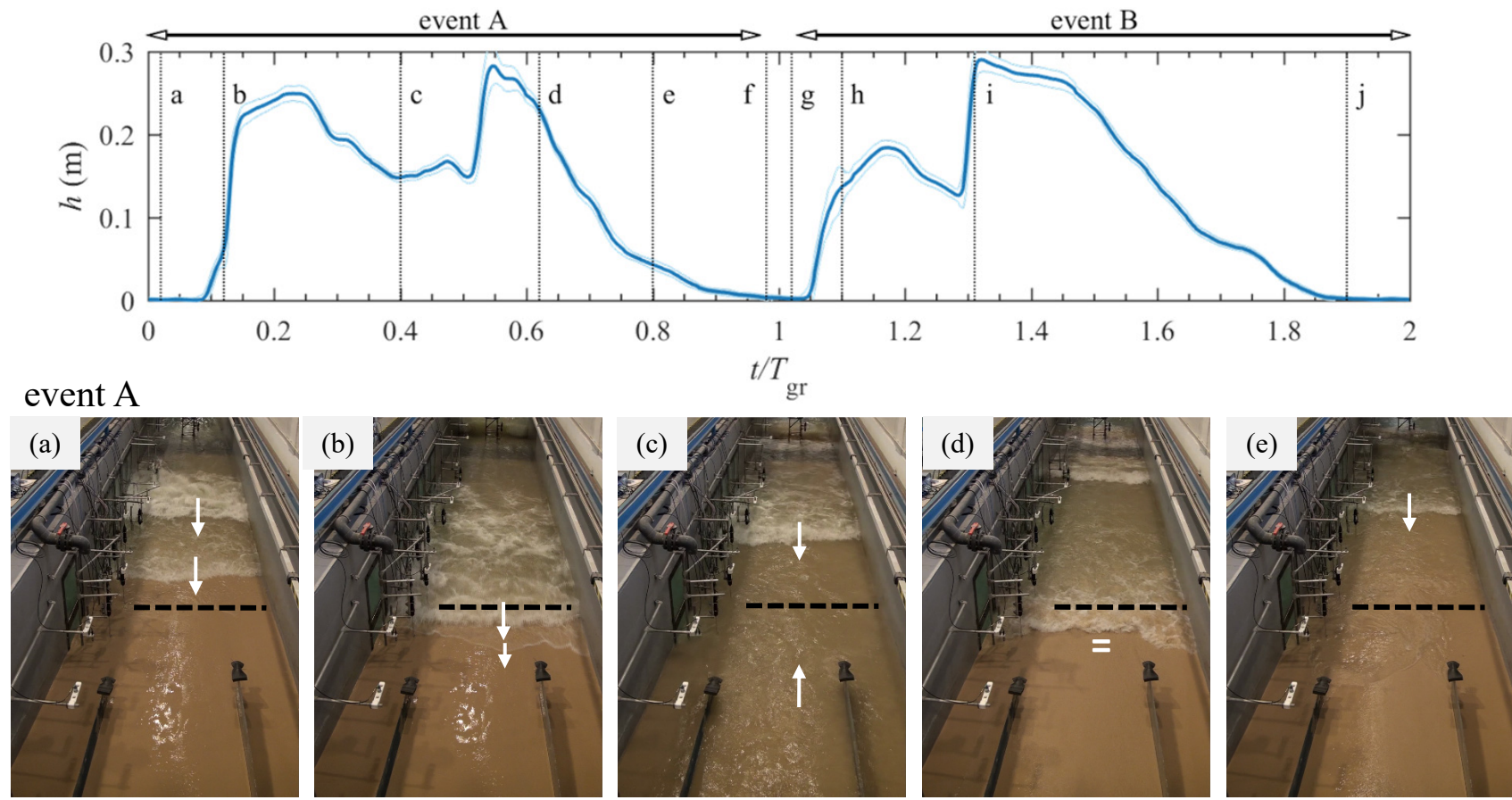

event B
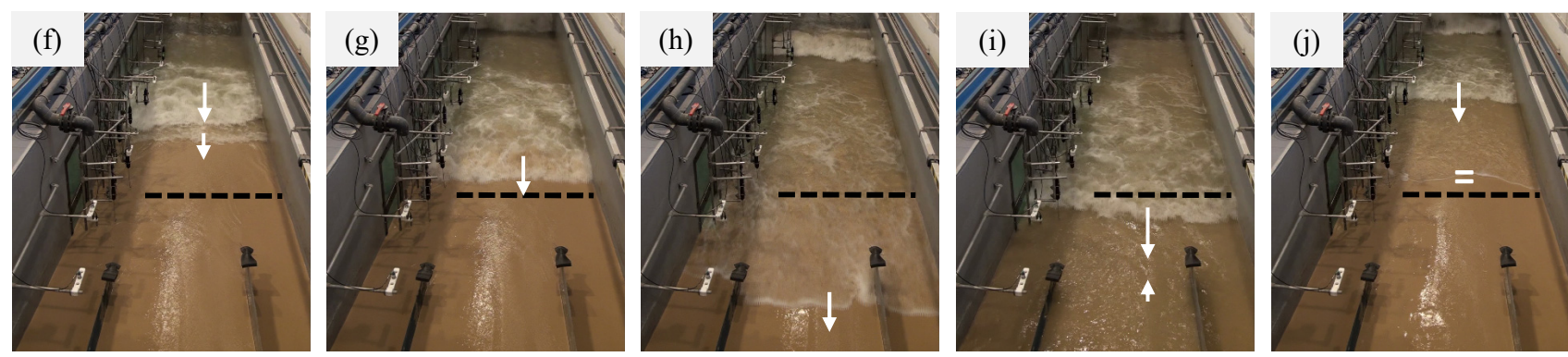

Figure 5: Top panel: time series of the phase-averaged water depth at $x=1.25 \mathrm{~m}$ (location corresponding to $\mathrm{CCM}^{+}$tank 1), measured by AWG (solid line: ensemble-mean; dashed lines: +/- one standard deviation). Lower panels show snapshots of a video recording (a-j) with reference to time instants in upper panel. The black dashed line in the photos marks the location of the water surface measurement in the top panel; the white arrows mark the direction of incident bores and the backwash flow. 


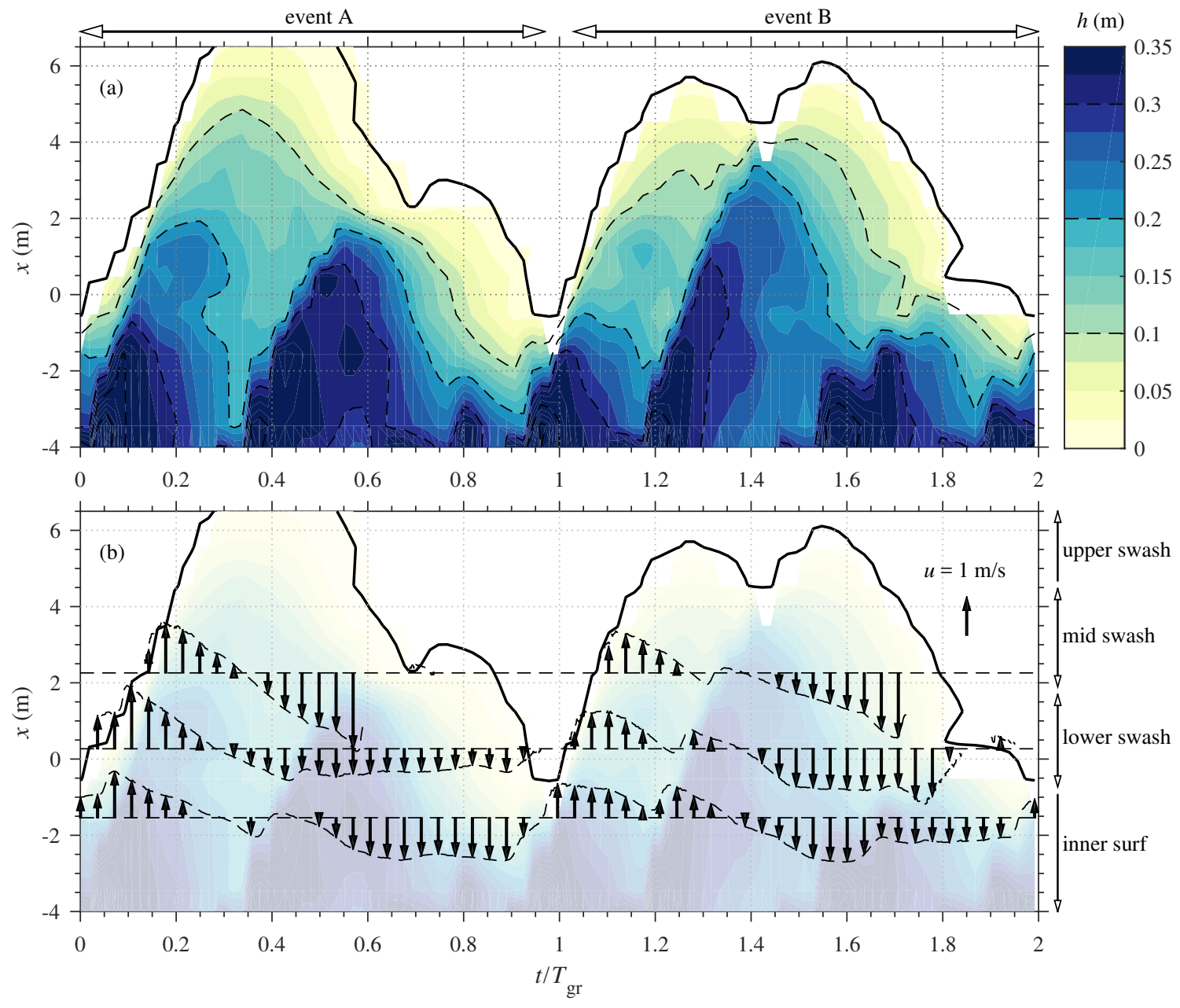

Figure 6: (a) Colour contour of water depth in swash zone; thick solid line denotes the $h$ $=0.01 \mathrm{~m}$ isoline (proxy for instantaneous shoreline location), dashed lines denote the $h$ $=0.10,0.20$, and $0.30 \mathrm{~m}$ isolines; (b) As (a), but with the cross-shore velocity at three cross-shore locations superimposed as vectors. 

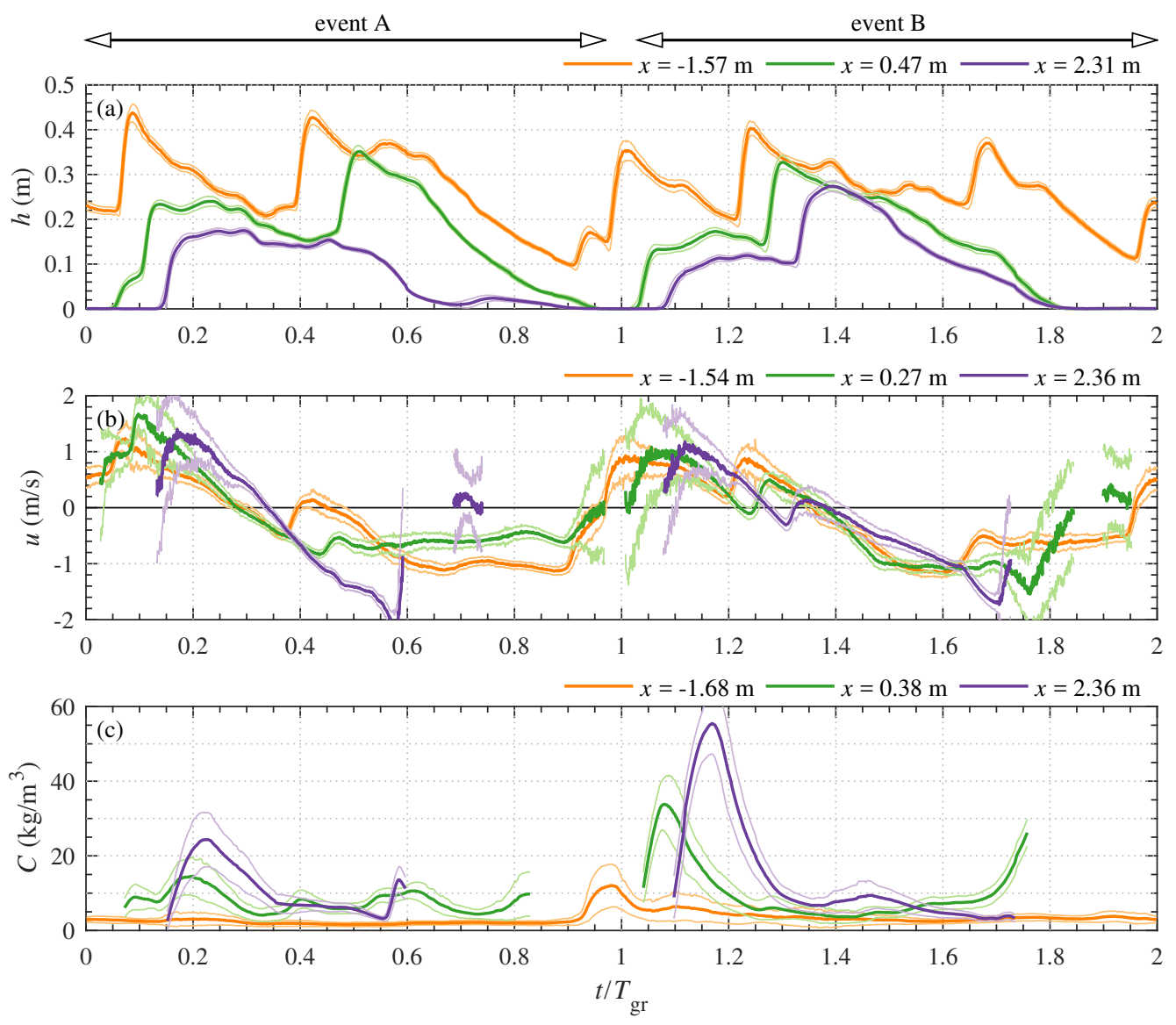

Figure 7: Water depth (a), cross-shore velocity (b) and suspended sand concentration (c) at three cross-shore locations in the swash zone. Velocity and sand concentration were measured at $z-z_{\text {bed }}=0.03 \mathrm{~m}$. Thick line represents the ensemble-mean, thin lines mark $+/$ - standard deviation. 

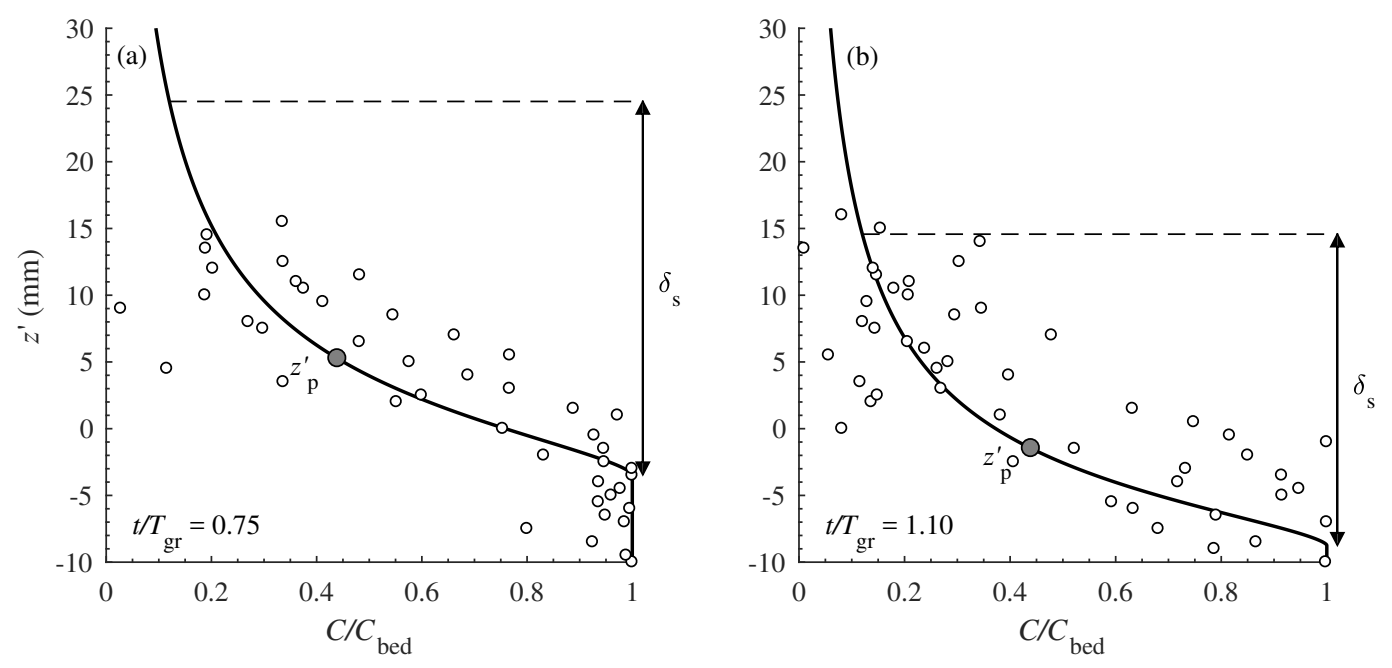

Figure 8: Illustration of Equation 2 (O'Donoghue and Wright, 2004a) fit to $\mathrm{CCM}^{+}$concentration measurements. White circles mark the measured $C\left(z, t / T_{\mathrm{gr}}\right)$ at $x=1.28 \mathrm{~m}$. Solid black line represents the fit, the grey circle marks the elevation of the sheet flow layer pivot point. 


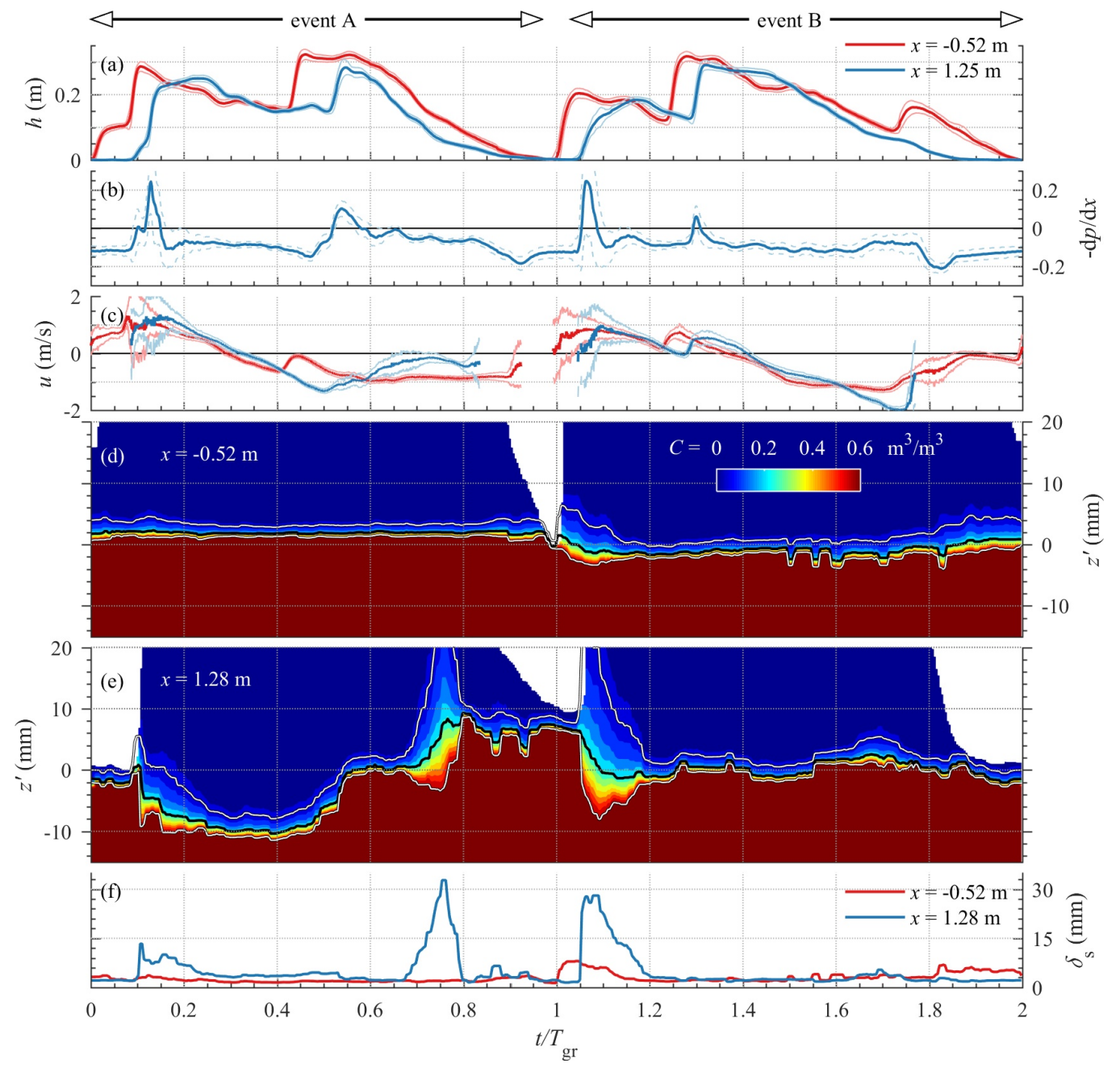

Figure 9: Phase-averaged hydrodynamics and sheet flow dynamics at the two $\mathrm{CCM}^{+}$locations in the lower swash zone. (a) Water depths (mean +/- standard deviation); (b) Cross-shore pressure gradients at the location of $\mathrm{CCM}^{+} \operatorname{tank} 1$ (mean +/- standard deviation); (c) Cross-shore velocities (mean +/- standard deviation); (d, e) Vertical distribution of concentrations in the sheet flow layer, obtained by Equation 2 fit to $\mathrm{CCM}^{+}$measurements. Solid black line denotes the sheet flow layer pivot point, white lines mark the sheet flow layer top and bottom; (f) Sheet flow layer thickness at both locations. 

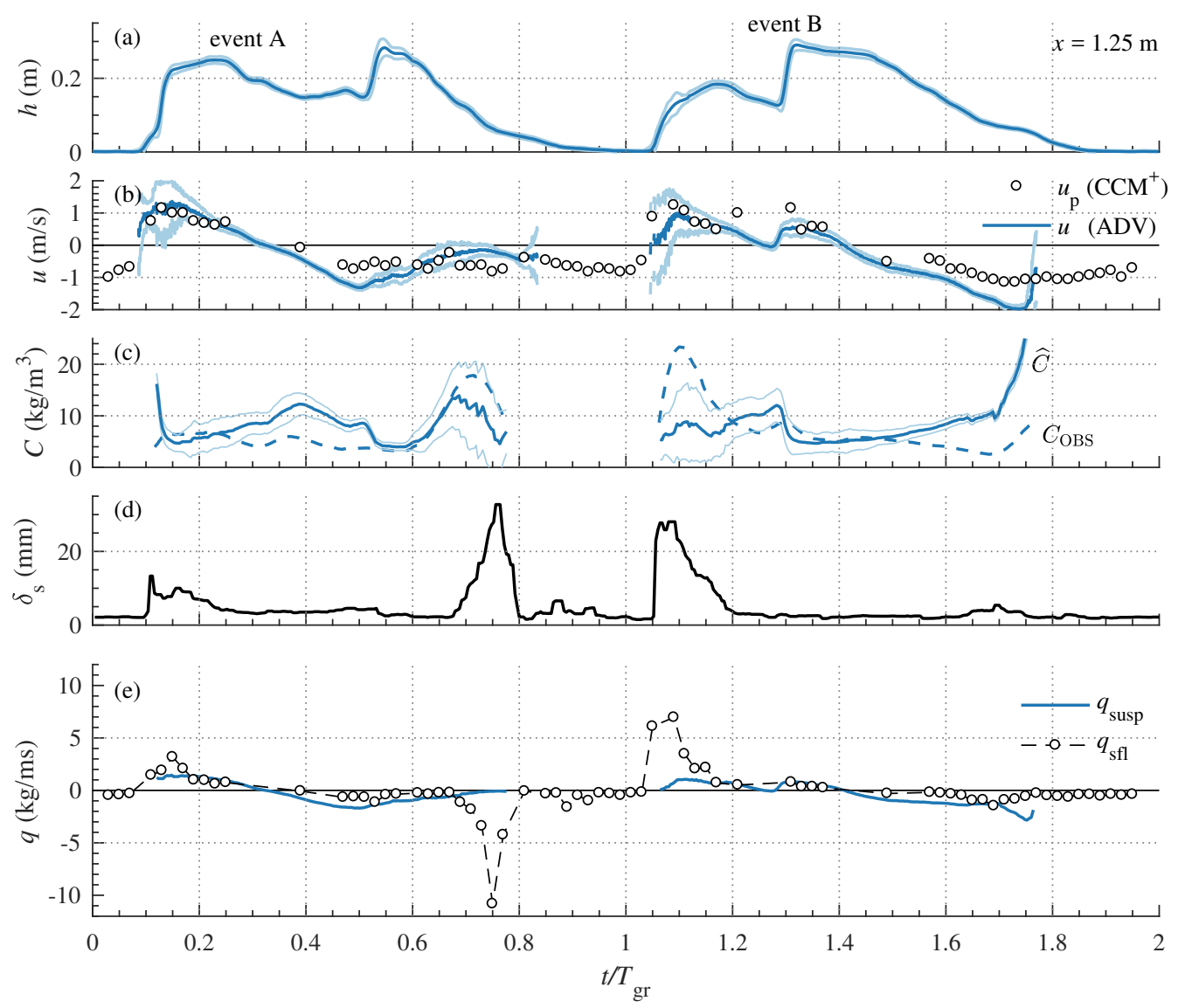

Figure 10: Depth-integrated transport rates at the location of $\mathrm{CCM}^{+} \operatorname{tank} 1(x=1.28$ m). (a). Water depth; (b) Flow velocity measured by ADV at $z-z_{\text {bed }}=0.03 \mathrm{~m}$ (solid lines; mean +/- standard deviation) and particle velocity measured by $\mathrm{CCM}^{+}$at the top of the sheet flow layer (circles); (c) Suspended sand concentration, measured by OBS at $z-z_{\text {bed }}=0.03 \mathrm{~m}$ (dashed) and depth-averaged following Equation 7 (solid); (d) Sheet flow layer thickness; (e) Depth-integrated suspended (blue solid line) and sheet flow layer (circles and dashed line) sand transport rates. 

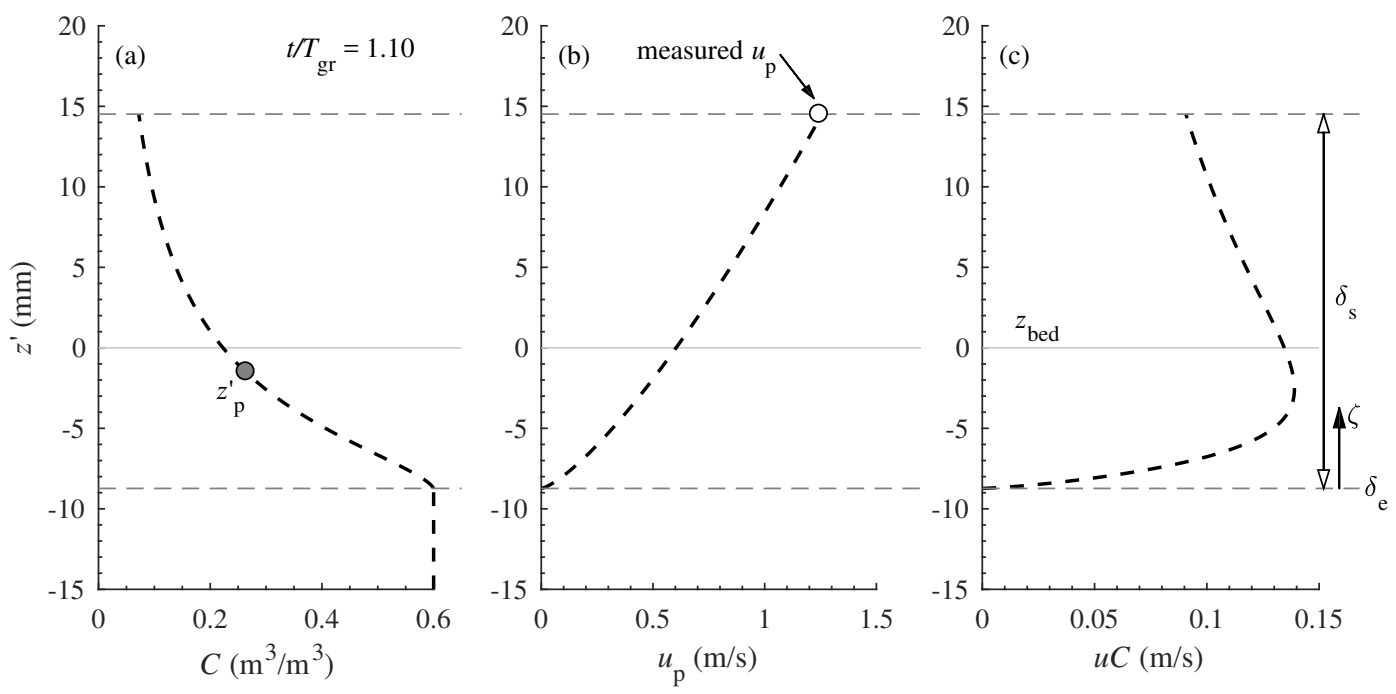

Figure 11: Illustration of sheet flow sand flux calculations. (a) Concentration profile (Equation 2); (b) Vertical profile of the cross-shore velocity: the circle shows the measured particle velocity by the $\mathrm{CCM}^{+}$, dashed line shows the distribution following Equation 8; (c) Resulting flux distribution $\phi=u C$. 

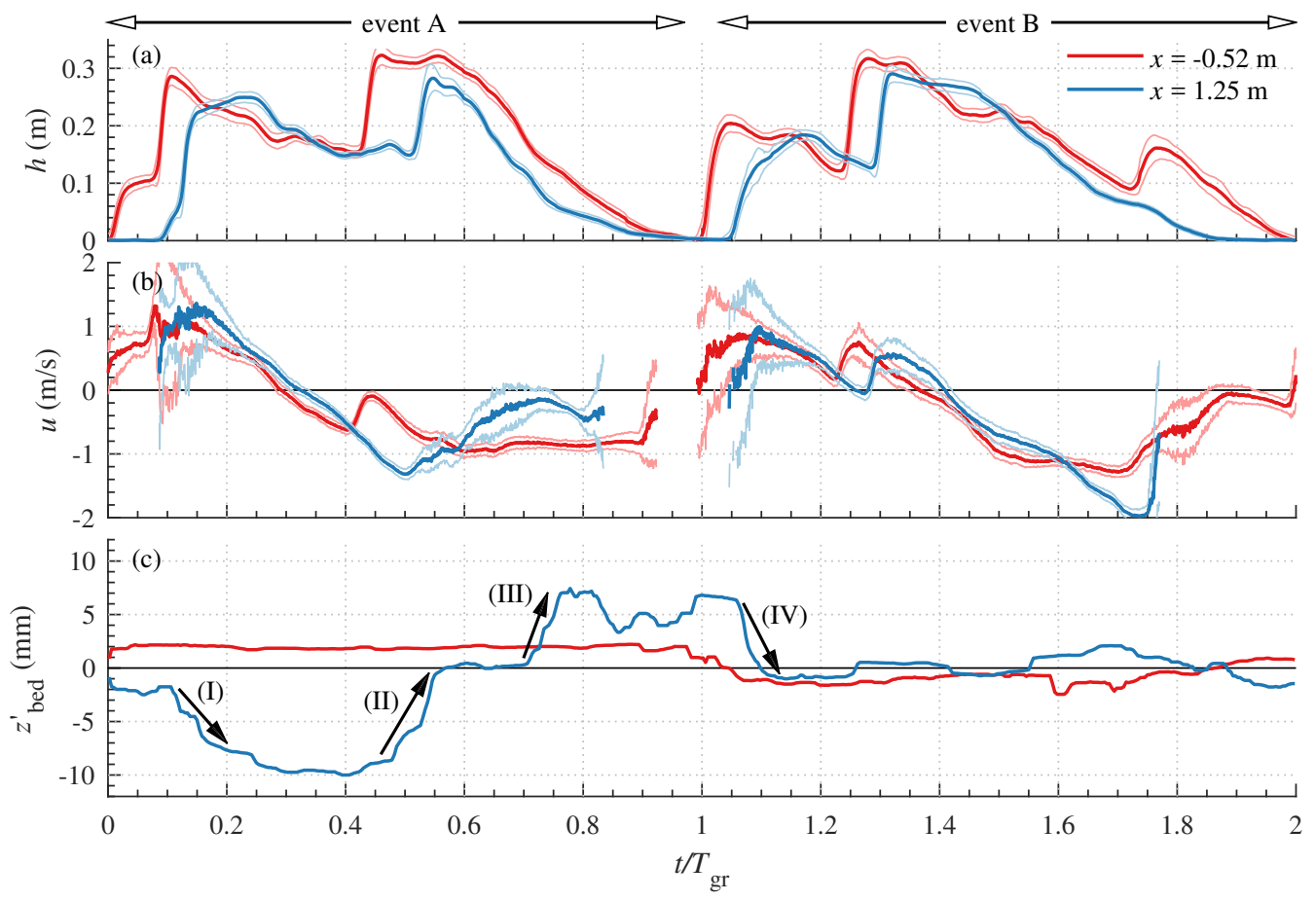

Figure 12: Intra-swash hydrodynamics and bed level at both $\mathrm{CCM}^{+}$locations (blue: $\mathrm{CCM}^{+}$tank 1, red: tank 2). (a) Water depths; (b) Velocity; (c) Bed level measurements by $\mathrm{CCM}^{+}$, with I-IV indicating pick-up and deposition events that are discussed in the main text. 


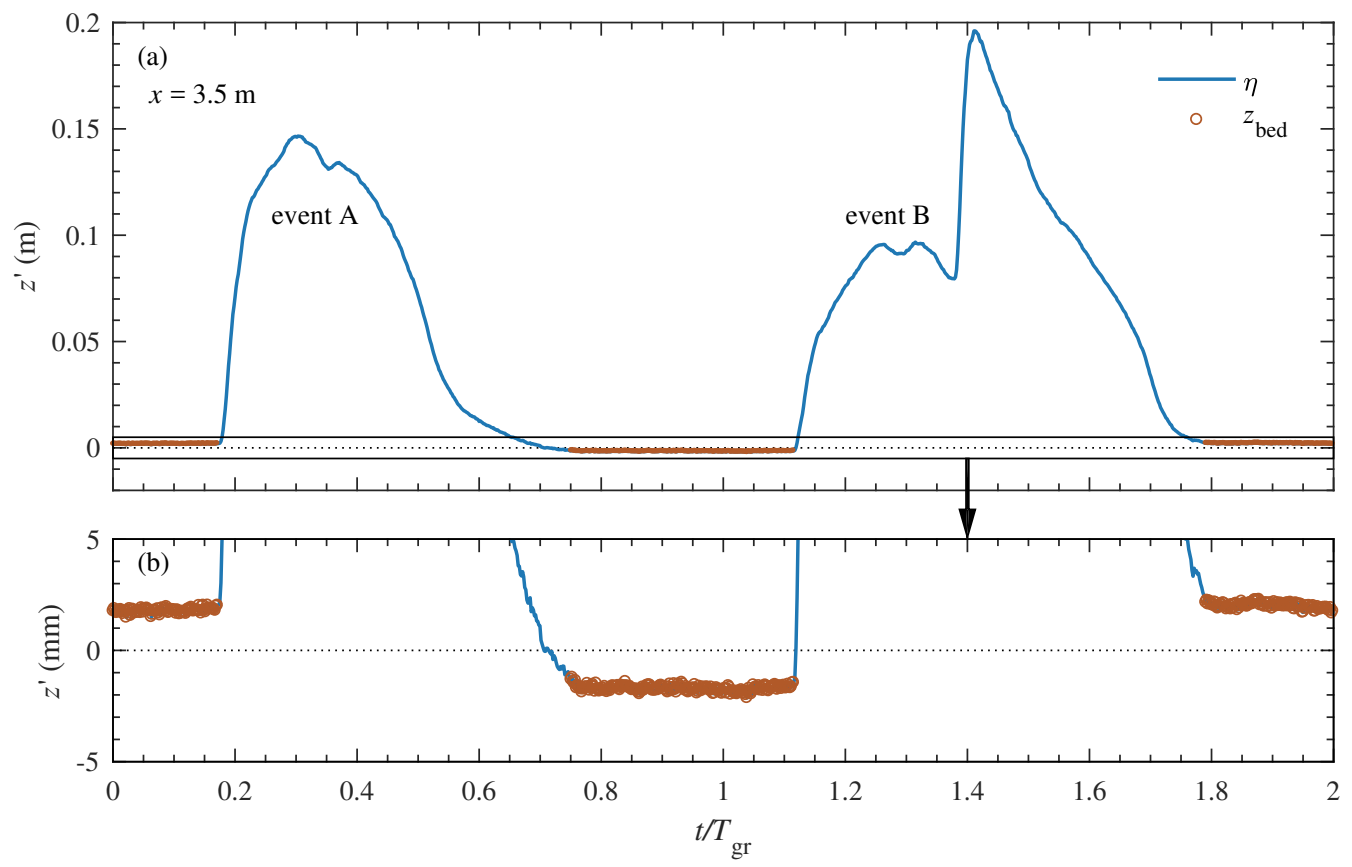

Figure 13: Illustration of bed level measurement by AWG: blue solid lines show the phaseaveraged AWG measurement, brown circles show the identified exposed bed level. (b) shows a close-up of (a). 

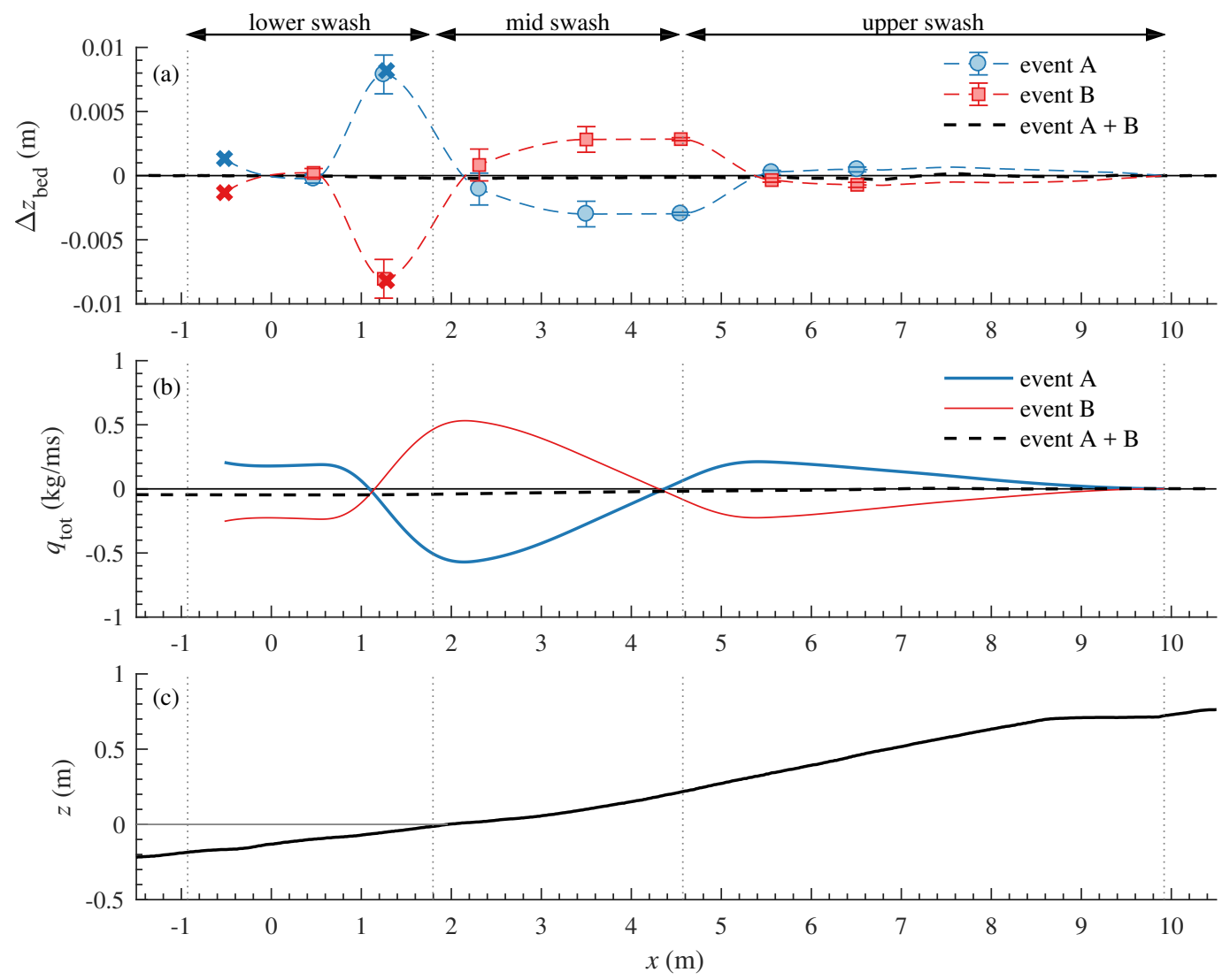

Figure 14: (a) Net bed level change by swash events A (blue) and B (red), measured by AWG (circles: event A; squares: event B) and $\mathrm{CCM}^{+}$(crosses), and cubic interpolation of the measurements (dashed lines); (b) Mean sand transport rates over events A (blue) and B (red), calculated from the net bed level changes, and the mean sand transport rate over both events obtained from the bed profile measurements (black dashed; previously also shown in Figure 2b); (c) Final bed profile. 